\title{
Selective and Sequential Aminolysis of Benzotrifuranone: Synergism of Electronic Effects and Ring Strain Gradient
}

Citation for published version (APA):

Baker, M. B., Ferreira, R. B., Tasseroul, J., Lampkins, A. J., Al Abbas, A., Abboud, K. A., \& Castellano, R. K. (2016). Selective and Sequential Aminolysis of Benzotrifuranone: Synergism of Electronic Effects and Ring Strain Gradient. Journal of Organic Chemistry, 81(19), 9279-9288. https://doi.org/10.1021/acs.joc.6b01867

Document status and date:

Published: 07/10/2016

DOI:

10.1021/acs.joc.6b01867

Document Version:

Publisher's PDF, also known as Version of record

\section{Document license:}

Taverne

Please check the document version of this publication:

- A submitted manuscript is the version of the article upon submission and before peer-review. There can be important differences between the submitted version and the official published version of record.

People interested in the research are advised to contact the author for the final version of the publication, or visit the DOI to the publisher's website.

- The final author version and the galley proof are versions of the publication after peer review.

- The final published version features the final layout of the paper including the volume, issue and page numbers.

Link to publication

\footnotetext{
General rights rights.

- You may freely distribute the URL identifying the publication in the public portal. please follow below link for the End User Agreement:

www.umlib.nl/taverne-license

Take down policy

If you believe that this document breaches copyright please contact us at:

repository@maastrichtuniversity.nl

providing details and we will investigate your claim.
}

Copyright and moral rights for the publications made accessible in the public portal are retained by the authors and/or other copyright owners and it is a condition of accessing publications that users recognise and abide by the legal requirements associated with these

- Users may download and print one copy of any publication from the public portal for the purpose of private study or research.

- You may not further distribute the material or use it for any profit-making activity or commercial gain

If the publication is distributed under the terms of Article 25fa of the Dutch Copyright Act, indicated by the "Taverne" license above, 


\section{Selective and Sequential Aminolysis of Benzotrifuranone: Synergism of Electronic Effects and Ring Strain Gradient}

Matthew B. Baker, ${ }^{\dagger}$ Renan B. Ferreira, Jonathan Tasseroul, Andrew J. Lampkins, Alexandre Al Abbas, Khalil A. Abboud, and Ronald K. Castellano*

Department of Chemistry, University of Florida, P.O. Box 117200, Gainesville, Florida 32611, United States

Supporting Information

ABSTRACT: Benzotrifuranone (BTF), bearing three symmetry-equivalent lactone rings, is unique in its ability to undergo highly selective and sequential aminolysis reactions in one-pot to afford multifunctionalized molecules $(>80 \%$ overall yield). New insight into this behavior is presented through kinetics measurements (by stopped-flow IR spectroscopy), Xray crystal structure analysis, quantum chemical calculations, and comparison of BTF to other benzoate esters, including its ring expanded congener benzotripyranone (BTP). While the structure-property investigation confirms stepwise electronic/

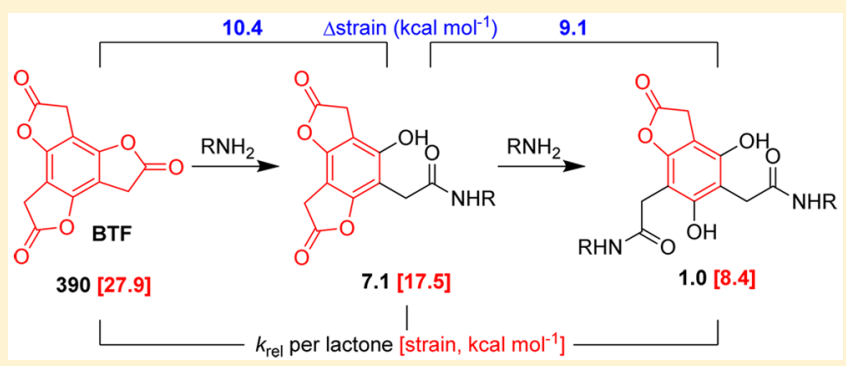
inductive lactone deactivation for both BTF and BTP, the unusually fast and selective aminolysis of BTF is only fully explained through synergistic ring strain effects. Experimental signatures of the significant ring strain of BTF $\left(\sim 28 \mathrm{kcal} \mathrm{mol}^{-1}\right.$ based on DFT calculations vs $17 \mathrm{kcal} \mathrm{mol}^{-1}$ for BTP) include its high lactone carbonyl stretching energy $\left(1821 \mathrm{~cm}^{-1}\right.$ in acetonitrile vs $1777 \mathrm{~cm}^{-1}$ for BTP) and bond length alternation within its benzenoid ring. While ring strain is relieved upon the sequential aminolysis of both BTF and BTP, it is only for the former that a ring strain gradient is established that contributes to the stepwise aminolysis rate differences and enhanced selectivity. The work shows how a combination of electronic effects and ring strain can underpin the design of small molecules capable of stepwise functionalization, of which there are notably few examples.

\section{INTRODUCTION}

Synthetic methodology to rapidly and efficiently prepare multifunctional molecules continues to leverage discoveries in disciplines spanning materials science and chemical biology. Particularly attractive are protocols that provide access to complex targets through a series of reactions in a single pot, as they potentially reduce purification costs, eliminate waste, and lend themselves to diversity-oriented synthesis. ${ }^{1}$ Excellent progress has been made to develop one-pot domino and multicomponent reactions along these lines. ${ }^{2}$ An alternative approach to discrete multifunctional architectures is exemplified by the chemistry of cyanuric chloride $(\mathbf{C C})^{3}$ and its congeners (Figure 1a), wherein a highly symmetrical scaffold is efficiently desymmetrized, in one pot, through sequential substitution reactions across a convenient temperature range. ${ }^{4}$ As the paradigmatic framework displaying this reactivity profile, CC has facilitated access to diverse multifunctional targets for applications across the biological, ${ }^{5}$ supramolecular, ${ }^{6}$ synthetic, ${ }^{7}$ and materials sciences. ${ }^{8}$

The paucity of available scaffolds akin to CC speaks to the stringent kinetics requirements for a molecule with even three symmetry equivalent reactive sites to undergo synthetically useful stepwise functionalization. Given identical rates of reaction between any of sites $\mathrm{A}, \mathrm{A}^{\prime}$, or $\mathrm{A}^{\prime \prime}$ with reagent site $\mathrm{B}$ (i.e., $k_{\mathrm{AB}}=k_{\mathrm{A}^{\prime} \mathrm{B}}=k_{\mathrm{A}^{\prime \prime} \mathrm{B}}$ ), a simple mathematical model (see the SI for details) predicts a paltry $44 \%$ maximum yield of the singly functionalized product and an abysmal start to the synthesis of a fully differentiated target (Figure 1b). An ideal system establishes a reactivity gradient (i.e., $k_{\mathrm{AB}} \gg k_{\mathrm{A}^{\prime} \mathrm{B}} \gg k_{\mathrm{A}^{\prime \prime} \mathrm{B}}$ ) and allows (i) efficient conversion of the starting material to the mono-, di-, and trifunctionalized products provided reagent stoichiometric control and (ii) the sequential introduction of up to three different reagents. To the best of our knowledge, scaffolds fitting this reactivity paradigm have yet to be targets of systematic mechanistic/kinetic investigation, ${ }^{9}$ and therefore de novo design.

We recently reported ${ }^{10}$ that benzotrifuranone $(\mathbf{B T F})^{11}$ (Scheme 1), a $C_{3 \mathrm{~h}}$-symmetrical trilactone, is unusually suited for multifunctionalization through sequential aminolysis reactions. The platform affords rapid and efficient access to mono- (e.g., 1R), di- (e.g., 2RR), and trifunctionalized (e.g., 3RRR) targets provided routine control of temperature and amine reagent stoichiometry, and lends itself to the one-pot synthesis of multifunctionalized phloroglucinol, 3 (e.g., $\left.3 \mathbf{R}^{1} \mathbf{R}^{2} \mathbf{R}^{3}\right)$, from BTF in good yield (>80\%) and in a single day.

We initially proposed a primarily electronic/inductive argument (given the stepwise substituent changes occurring on the central benzenoid ring) to rationalize the kinetic deactivation observed upon successive aminolysis of BTF. ${ }^{10}$ In this paper, we report a more comprehensive understanding of the aminolysis behavior of BTF through kinetics measure-

Received: August 1, 2016

Published: August 31, 2016 
(a)

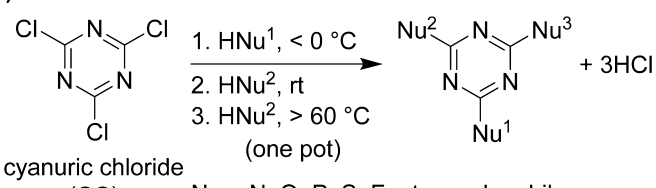$$
\text { (CC) } \quad \mathrm{Nu}=\mathrm{N}, \mathrm{O}, \mathrm{P}, \mathrm{S}, \mathrm{F} \text {, etc. nucleophile }
$$

(b)

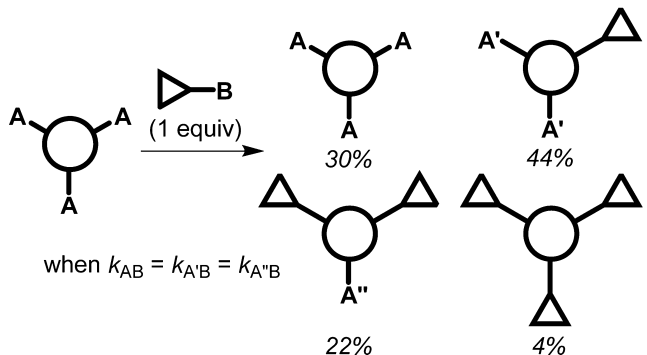

Figure 1. Outcomes for functionalization of a molecule bearing three symmetry equivalent reactive positions. (a) Efficient one-pot sequential multifunctionalization, exemplified by the chemistry of cyanuric chloride (CC), requires establishment of a reactivity (kinetic) gradient. (b) A statistical product mixture (percentages shown are from mathematical modeling) results if the reaction rates between reagent site $\mathrm{B}$ and positions $\mathrm{A}, \mathrm{A}^{\prime}$, and $\mathrm{A}^{\prime \prime}$ are identical (assuming an irreversible reaction that goes to completion).

Scheme 1. Summary of Aminolysis Behavior of Benzotrifuranone (BTF) ${ }^{a}$

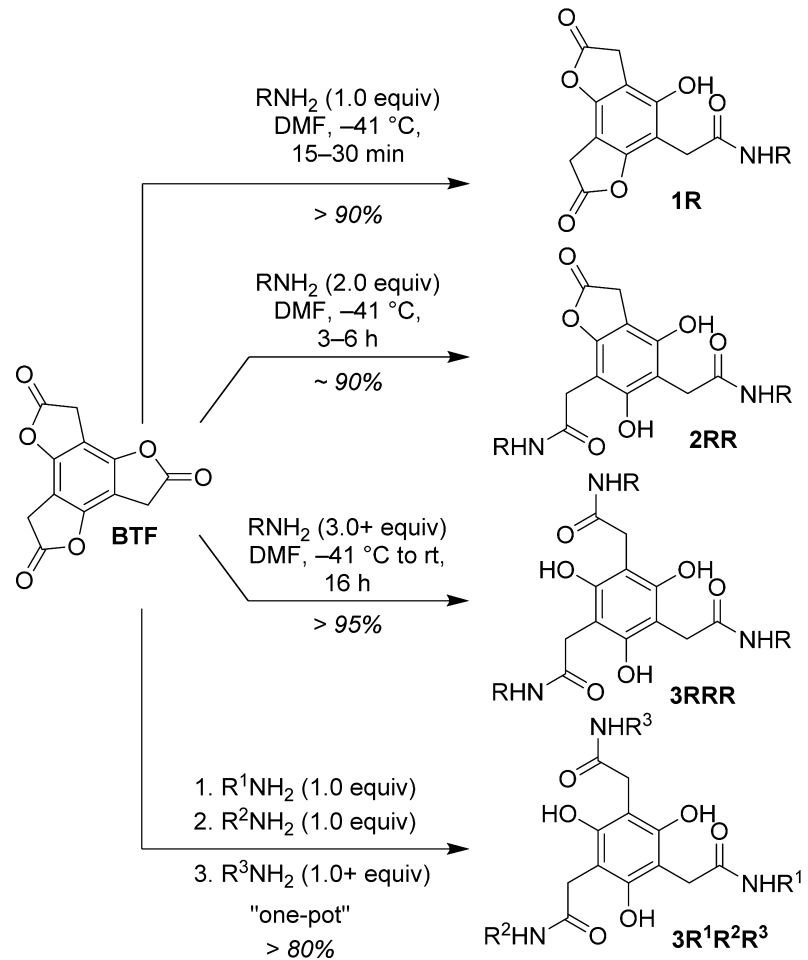

${ }^{a}$ Summary of BTF aminolysis reactivity from ref 10 . Yields shown are representative and determined from either ${ }^{1} \mathrm{H}$ NMR (1R, 2RR) or isolation (3RRR, $3 R^{1} R^{2} R^{3}$ ).

ments, X-ray crystal structure analysis, and quantum chemical calculations. Included is comparison of BTF to various benzoate esters, such as a ring expanded congener, benzotripyranone (BTP) (Chart 1). Notably, our structure-property investigation exposes a ring strain gradient as a component of the sequential aminolysis behavior observed for BTF. While
Chart 1. Benzoate Ester Derivatives and Amines Used in This Work

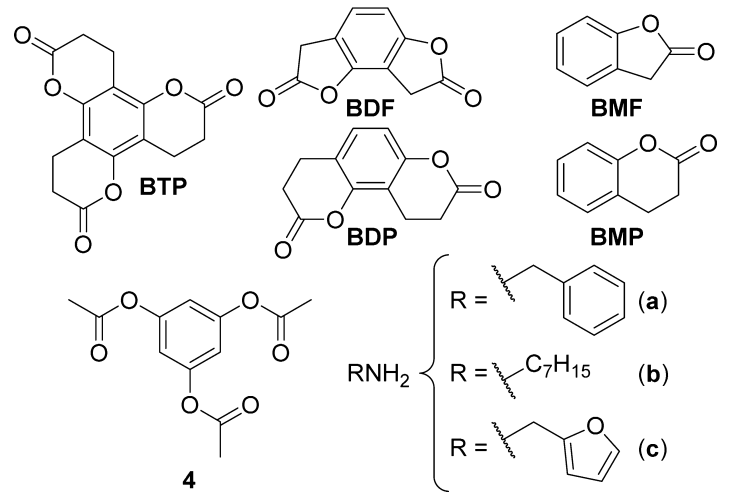

singular strain elements are appreciated as useful promoters of chemical reactions, ${ }^{12}$ this study shows that energetically coupled strain-release events can afford stepwise reactivity and can serve as the basis for sequential molecular functionalization.

\section{RESULTS AND DISCUSSION}

Numbering Convention. Throughout the article, BTF and BTP aminolysis products are first numbered based on their parent structure. Letters after the numbers designate the number, type, and sequence of amines (Chart 1) used to form the aminolysis product. For example, compound $\mathbf{1}$ (Scheme 1) produced by aminolysis of BTF with one equivalent of amine a will be denoted 1a, while 2 produced from BTF using two equivalents of amine a will be denoted 2aa, and so on.

Benzoate Esters Used in This Work (Chart 1). BTF, BMF (2-coumaranone), ${ }^{11}$ and 4 (phloroglucinol triacetate) were synthesized following literature precedent (see the SI for details); BMP (3,4-dihydrocoumarin) was purchased commercially. The synthesis of benzotripyranone BTP, a new compound, could be completed quantitatively through acidcatalyzed intramolecular transesterification of known triisopropyl 3,3',3'-(2,4,6-trihydroxybenzene-1,3,5-triyl)tripropio-nate (which is available in six steps $^{13}$ from 1,3,5trimethoxybenzene). Noted previously, ${ }^{11}$ attempts to prepare BTF using "reversible" (e.g., Lewis and Brønsted acid catalyzed) lactonization conditions were plagued by the formation of stable, partially cyclized intermediates. The observation that BTP is formed quantitatively under the same conditions speaks to its relative thermodynamic stability. The remaining compounds shown in Chart 1, BDF and BDP, have been used exclusively in calculations (vide infra).

General Aminolysis Behavior: BTF vs BTP. BTP, like BTF, forms a dilactone (5a) as the major product upon reaction with one equivalent of an aliphatic amine like benzylamine (a) (Scheme 2). The reaction, however, under conditions identical to BTF aminolysis, is considerably slower and lower yielding with respect to the monoaminolysis adduct (i.e., the reaction is less selective). HPLC analysis (see Figure $\mathrm{S} 1$ ) of the crude reaction after $2 \mathrm{~h}$ (at $-41{ }^{\circ} \mathrm{C}$ in DMF), for example, reveals a mixture of BTP (16\%), 5a (70\%), and 6aa (14\%) (and no detectable 7aaa). The conversion to 5a, nonetheless, exceeds predictions given equivalent lactone reactivity (44\%). Similar results are found (not shown in Scheme 2) upon reaction of BTP with $n$-hepylamine (b) (where $\mathbf{5 b}$ is prepared in $71 \%$ isolated yield). Treatment of 
Scheme 2. Representative Aminolysis of Benzotripyranone (BTP $)^{a}$

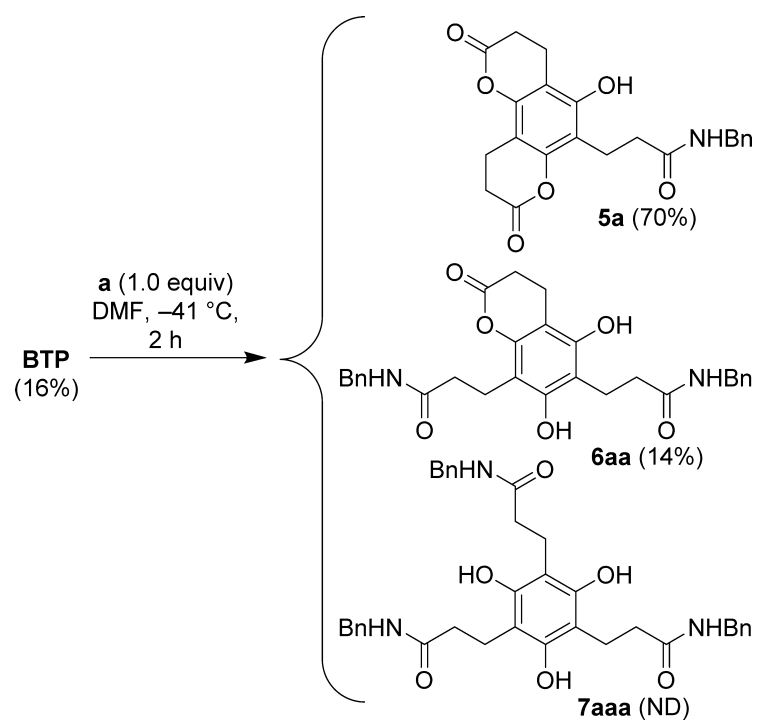

${ }^{a}$ Percentages shown in parentheses are relative amounts of BTP, 5a, 6aa, and 7aaa based on HPLC analysis of the crude reaction mixture after $2 \mathrm{~h}$. The isolated yield of $\mathbf{5 a}$, in a separate preparation under similar conditions, is comparable (see the SI for details). ND = not detected

BTP with two equivalents of $\mathbf{a}$ or $\mathbf{b}$ provides the corresponding monolactones (6aa and $\mathbf{6 b b}$, respectively) in $\sim 60 \%$ yield, again exceeding the $50 \%$ predicted from equally reactive lactones. Phloroglucinol 7 can be prepared essentially quantitatively with an excess of amine (and warming to room temperature overnight) as shown through the preparation of $7 \mathbf{b b b}$ (see the SI for details). These synthetic experiments give the first indication that a simple inductive argument is not sufficient to explain the high selectivity of BTF aminolysis.

Aminolysis Rate Constants: Determination and Caveats. The aminolysis of simple phenyl acetates in polar aprotic solvents has been extensively studied from both an experimental $^{14}$ and a theoretical point of view. ${ }^{14 \mathrm{~b}, 15}$ Typically, second-order kinetics (first order in amine and ester) are observed, ${ }^{14 \mathrm{~b}-\mathrm{e}}$ although some studies have presented evidence for a third order process. ${ }^{14 f, 16}$ In light of this data, pseudo-firstorder conditions generally using an excess of amine, $n$ heptylamine (b), were established for determination of aminolysis rate constants for BTF and BTP, their products, and selected simpler systems (Chart 1). Due to the rapid aminolysis of BTF, the aminolysis rates were measured in all cases by stopped-flow FT-IR spectroscopy (Table 1 and Table S1), approximated by the rate of disappearance of the relevant lactone $\mathrm{C}=\mathrm{O}$ absorptions (Figure $2 \mathrm{a}$ and Figure S2). All measurements were made in acetonitrile, a solvent which provided a good window of visibility $\left(1750-1800 \mathrm{~cm}^{-1}\right)$ at $24.0 \pm 0.2^{\circ} \mathrm{C}$.

The $n$-heptylaminolysis of BTP (Figure 2b) is illustrative. An absorption difference plot $\left(A-A_{0}\right)$ over the first minute accentuates the change in the BTP $\mathrm{C}=\mathrm{O}$ absorption at 1776 $\mathrm{cm}^{-1}$ (and accompanying increase in amide $\mathrm{I}(\mathrm{C}=\mathrm{O})$ absorption, $\sim 1640 \mathrm{~cm}^{-1}$, not shown). While data used for determination of $k_{\mathrm{obs}}$ was limited to the early (and linear) portion of the pseudo-first-order rate plot, it is critical to appreciate that the absorption maxima for the lactones along
Table 1. Aminolysis Rate Constants ${ }^{a}$

\begin{tabular}{lll} 
compound & \multicolumn{1}{c}{$k_{\mathrm{lac}}\left(\mathrm{M}^{-1} \mathrm{~s}^{-1}\right),[k]^{b}$} & $k_{\mathrm{lac}, \mathrm{re},},\left[k_{\mathrm{rel}}\right]^{c}$ \\
$\mathbf{~ B T F}$ & $4.87 \pm 0.06[14.6 \pm 0.2]$ & $934[2802]$ \\
$\mathbf{1 b}$ & $0.0890 \pm 0.0050[0.178 \pm 0.010]$ & $17[34]$ \\
$\mathbf{2 b b}$ & $0.0126 \pm 0.0014$ & 2.4 \\
$\mathbf{B T P}$ & $0.0277 \pm 0.0001[0.0830 \pm 0.0003]$ & $5.3[16]$ \\
$\mathbf{5 b}$ & $0.0295 \pm 0.0002[0.0590 \pm 0.0003]$ & $5.7[11]$ \\
$\mathbf{6 b b}$ & $0.00682 \pm 0.00026$ & 1.3 \\
$\mathbf{B M F}$ & $0.0128 \pm 0.0003$ & 2.5 \\
$\mathbf{B M P}$ & $0.00521 \pm 0.00019$ & 1.0 \\
$\mathbf{4}$ & $0.00230 \pm 0.00007[0.00691 \pm 0.00022]$ & $0.4[1.3]$
\end{tabular}

${ }^{a}$ Experimental rate constants determined for $n$-heptylaminolysis under pseudo-first-order conditions at $24.0 \pm 0.2{ }^{\circ} \mathrm{C}$ in acetonitrile. See the SI for details. ${ }^{b}$ Apparent second-order rate constants. $k_{\text {lac }}$ rates have been statistically corrected for the number of reactive carbonyl groups. Assumed is that the two different lactones within $\mathbf{1 b}$ and within $\mathbf{5 b}$ react comparably. The standard error shown is derived from 3-6 replicate runs. $k$ rates in brackets have not been statistically corrected and are obtained directly as $k_{\text {obs(average) }} /[n$-heptylamine $] .{ }^{c}$ Relative aminolysis rates with and without statistical correction for the number of reactive carbonyl groups.
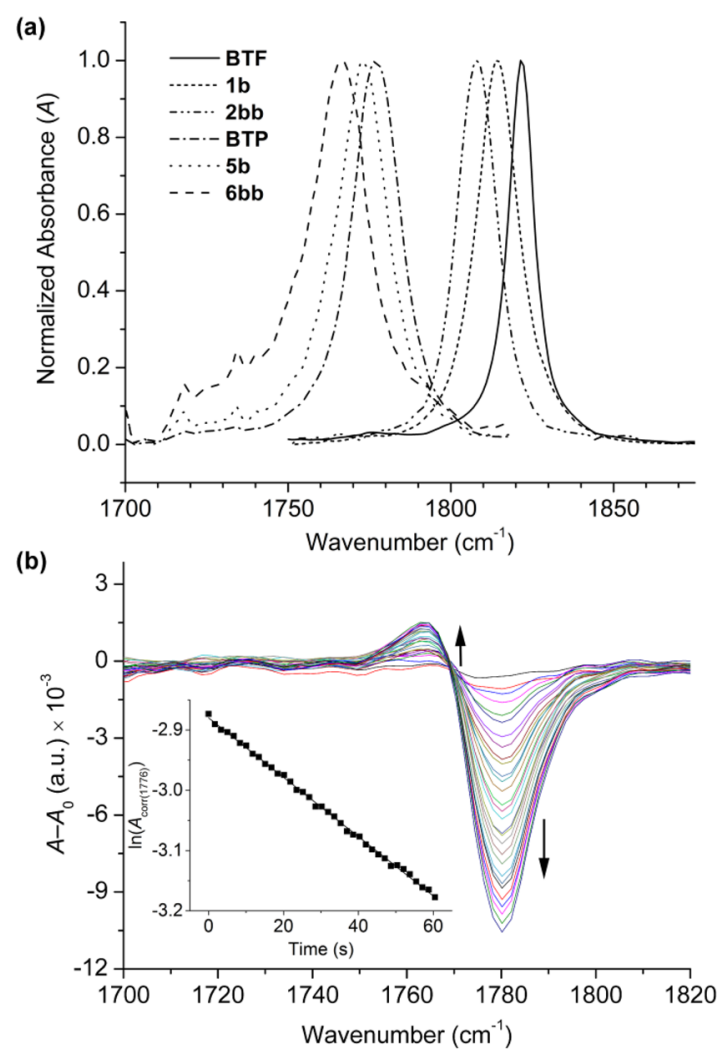

Figure 2. (a) Normalized IR absorption spectra (lactone $\mathrm{C}=\mathrm{O}$ region) of BTF, BTP, and their $n$-heptylaminolysis products recorded as dilute $\left(\sim 5 \times 10^{-3} \mathrm{M}\right)$ solutions in acetonitrile. (b) Representative $n$ heptylaminolysis data for BTP in acetonitrile at $24{ }^{\circ} \mathrm{C}([\mathrm{BTP}]=2.55$ $\mathrm{mM} ;[\mathbf{b}]=58.8 \mathrm{mM})$. IR difference spectra $\left(A-A_{0}\right.$; arrows show evolution with time) and the associated pseudo-first order kinetic plot are shown. Results of linear regression analysis: $k_{\mathrm{obs}}=0.00488 \mathrm{~s}^{-1}$; adjusted $R$-squared $=0.999$. See the SI for additional plots and full data analysis.

the aminolysis pathway for BTP are only modestly separated $\left(\Delta v_{\max } \sim 5 \mathrm{~cm}^{-1}\right)$ - such is also the case for BTF and 4. In this example, contaminating the diminishing BTP absorption at $1776 \mathrm{~cm}^{-1}$ are the increasing lactone $\mathrm{C}=\mathrm{O}$ absorptions for $\mathbf{5 b}$ 
Table 2. Predicted, Observed, and Statistical Aminolysis Product Outcomes for BTF and BTP ${ }^{a}$

\begin{tabular}{|c|c|c|c|c|c|c|}
\hline substrate & $\begin{array}{l}k_{1} / k_{2}(297 \mathrm{~K})^{b} \\
{\left[k_{1} / k_{2}, 233 \mathrm{~K}\right]^{c}}\end{array}$ & $\begin{array}{l}k_{1} / k_{3}(297 \mathrm{~K})^{b} \\
{\left[k_{1} / k_{3}, 233 \mathrm{~K}\right]^{c}}\end{array}$ & $\begin{array}{l}\text { A (\%, predicted) }{ }^{d}[\mathrm{~A}, \%, \\
\left.\text { observed, }^{e} \text { statisticalf }\right]\end{array}$ & $\begin{array}{l}\text { P1 (\%, predicted) }{ }^{d}[\mathrm{P} 1, \%, \\
\left.\text { observed, }^{e} \text { statistical }\right]\end{array}$ & $\begin{array}{c}\mathrm{P} 2 \text { (\%, predicted) }{ }^{d}[\mathrm{P} 2, \%, \\
\left.\text { observed, }^{e} \text { statistical }{ }^{\prime}\right]\end{array}$ & $\begin{array}{c}\mathrm{P} 3(\%, \text { predicted) })^{d}[\mathrm{P} 3, \%, \\
\left.\text { observed, }^{e} \text { statistical }\right]\end{array}$ \\
\hline BTF & $82.0[275]$ & 1160 [8050] & $1.2\left[<1,{ }^{g} 36\right]$ & $97.5\left[>96,{ }^{g} 37\right]$ & $1.2\left[<3,{ }^{g} 19\right]$ & $0.1\left[\mathrm{ND},{ }^{g} 8\right]$ \\
\hline ВTP & $1.41[1.54]$ & $12.2[24.2]$ & $27.8[16,36]$ & $45.0[70,37]$ & $26.7[14,19]$ & $0.5[\mathrm{ND}, 8]$ \\
\hline
\end{tabular}

${ }^{a}$ Product ratios assuming reaction of 1 equiv of starting material (A, BTF or BTP) and 1 equiv of $n$-heptylamine (B). ${ }^{b}$ Ratio of appropriate Table 1 rate constants (e.g., $k_{\mathrm{BTF}} / k_{1 \mathrm{~b}}$, selectivity factors) based on $n$-heptylaminolysis at $297 \mathrm{~K}$ in acetonitrile. ${ }^{c}$ Rate ratios extrapolated to $233 \mathrm{~K}$ based on Arrhenius analysis. ${ }^{d}$ Starting material and product percentages predicted from $233 \mathrm{~K}$ rate ratios. ${ }^{e}$ Observed (experimental) product percentages for $n$-heptylaminolysis in DMF at $233 \mathrm{~K}\left({ }^{1} \mathrm{H}\right.$ NMR yields for the first two entries; isolated yields for the last two entries). ${ }^{f_{\text {Starting }}}$ material and product percentages predicted when $k_{1} / k_{2}=k_{1} / k_{3}=1{ }^{g}$ Data taken from ref $10 . \mathrm{ND}=$ not detected.

at $\sim 1773 \mathrm{~cm}^{-1}$. Given the complication, the observed lactone disappearance of BTP has been corrected for the appearance of the lactones of BDP (using the molar absorptivity at 1776 $\mathrm{cm}^{-1}$, see SI for details). Therefore, this $A_{\text {corr }}$ accurately reflects the concentration of the molecular species, and the $k_{\text {obs }}$ is the real rate of disappearance, in this case, of BTP. Identical approaches were utilized for all molecules that have overlapping product peaks (i.e., BTF, $\mathbf{1 b}, \mathbf{5 b}$, and $\mathbf{4}$ ) Linear regression analysis (adjusted $R$-squared $=0.999$ ) of the $\ln \left(A_{\text {corr }}\right)$ versus $t$ plot (inset) confirms pseudo-first-order kinetics and offers a slope $\left(k_{\mathrm{obs}}\right)$ of $0.00488 \mathrm{~s}^{-1}$. The standard error in the rate based on six replicate runs (Table S1) is $\pm 0.4 \%$ (see the SI for details). Representative kinetic plots for all of the relevant compounds in this work are shown in Figures S3-S5.

Finally, conversion to apparent second-order rate constants $(k)$ comes through $k_{\text {obs }} /[$ amine]. For BTP, BTF, $\mathbf{1 b}, \mathbf{4}$, and $\mathbf{5 b}$, the rate constants have been further statistically corrected (by the number of similarly reactive carbonyl groups in the molecules) to facilitate comparison on a per lactone basis $\left(k_{\text {lac }}\right)$. Assumed, and borne out qualitatively in previous studies, ${ }^{10}$ is that the two different lactones within $\mathbf{1 b}$ and within $\mathbf{5 b}$ react comparably.

Aminolysis Kinetics: General Observations. Immediately apparent from the kinetics data (Table 1$)$ is the extremely rapid monoaminolysis of $\mathbf{B T F}$ at room temperature $(k=14.6$ $\left.\mathrm{M}^{-1} \mathrm{~s}^{-1}\right)$. The aminolysis rate $\left(k_{\mathrm{lac}(\mathrm{BTF})}\right.$, on a per-ester basis $)$ is 2 orders of magnitude faster than six-membered ring congener BTP, 22 times faster than $p$-nitrophenyl acetate (a conventional "activated ester") under comparable conditions, ${ }^{14 b}$ and 2300 times faster than acyclic triacetate 4. Also apparent is the reactivity gradient established within the BTF and BTP families, where the lactone rate differences along the aminolysis pathway are more disparate in the former $\left(k_{\text {lac }(\mathbf{B T F})}: k_{\text {lac }(\mathbf{1 b})}: k_{1 \mathrm{ac}(2 \mathbf{b} \mathbf{b})}=390: 7.1: 1.0\right.$ versus $\left.k_{\mathrm{lac}(\mathbf{B T P})}: k_{\mathrm{lac}(\mathbf{5 b})}: k_{\mathrm{lac}(\mathbf{6 b b})}=4 \cdot 1: 4.3: 1.0\right)$. The disparity translates directly into the sequential aminolysis selectivity differences observed for the two systems read out from product yields (i.e., Schemes 1 and 2). The difference in aminolysis rate for BMF

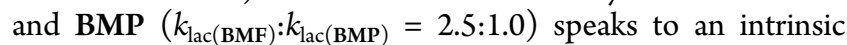
difference between the bicyclic rings (that contrasts with their alkaline hydrolysis profile where $\left.k_{\mathrm{lac}(\mathrm{BMF})}: k_{\mathrm{lac}(\mathbf{B M P})}=1 \cdot 0: 9.7^{17}\right)$. While the difference is mirrored in $k_{\mathrm{lac}(\mathbf{2 b b})}: k_{\mathrm{lac}(\mathbf{6 b})}=1.8: 1.0$, a departure in the ratio is noted as additional rings are added $\left(k_{\mathrm{lac}(\mathbf{B T F})}: k_{\mathrm{lac}(\mathbf{B T P})}=180: 1.0\right.$ and $\left.k_{\mathrm{lac}(\mathbf{1 b})}: k_{\mathrm{lac}(\mathbf{5 b})}=3.0: 1.0\right)$ in part as a consequence of cumulative ring-based (e.g., strain) effects (vide infra).

Aminolysis Kinetics: Relationship to Aminolysis Product Yields. The rate data shown in Table 1 should allow estimation of the aminolysis product distribution expected upon treatment of either BTF or BTP with one equivalent of $n$-heptylamine $\mathbf{b}$, and therefore a separate way to evaluate their consistency. Of note, this kinetic analysis is based on the statistically uncorrected rates $(k)$ since we are evaluating the selective production of chemical entities and not comparing functional groups as above. Aminolysis of BTF/BTP occurs through a series of three irreversible consecutive reactions and is therefore governed by the general kinetic expressions derived for "triply consecutive competitive systems". ${ }^{18}$ Since an analogous experimental kinetic analysis of CC has yet to be done, the work of Friedman and White ${ }^{19}$ that has specifically considered the following consecutive reaction sequence provides a generic starting point:

$$
\begin{aligned}
& \mathrm{A}+\mathrm{B} \stackrel{k_{1}}{\rightarrow} \mathrm{P} 1 \\
& \mathrm{P} 1+\mathrm{B} \stackrel{k_{2}}{\rightarrow} \mathrm{P} 2 \\
& \mathrm{P} 2+\mathrm{B} \stackrel{k_{3}}{\rightarrow} \mathrm{P} 3
\end{aligned}
$$

In the specific cases described in this work, A is either BTF or BTP, B is an amine nucleophile (e.g., b), P1 is a dilactone (i.e., 1 or 5), P2 is a monolactone (i.e., 2 or 6), and P3 is a phloroglucinol (i.e., 3 or 7 ).

Modification of the Friedman and White analysis to assume complete conversion of the amine and a 1:1 stoichiometry of reactants (i.e., $[\mathrm{A}]_{0}=[\mathrm{B}]_{0}$ ), an additional mass balance constraint can be introduced, and a relationship between rate ratios (or selectivity factors, $k_{1} / k_{\mathrm{i}}$ ) and the final product ratios can be derived (see the SI for details). The derivation allows the prediction of product ratios within a sequence given the rate constants, or estimation of the ratio of rate constants based on the experimental product ratios. When $k_{1}=k_{2}=k_{3}$ (i.e., where $\left.k_{1} / k_{2}=k_{1} / k_{3}=1\right)$ a statistical product distribution results from the analysis with $36 \%$ A, $37 \% \mathrm{P} 1,19 \% \mathrm{P} 2$, and 8.4\% P3 (Table S2). Satisfyingly, this distribution is essentially identical to the distribution determined by statistical modeling reported in our previous work $^{10}$ and discussed in the SI. Illustrative for this work, if one assumes the statistically corrected $k_{\text {lac }}$ rates are equal (i.e., $k_{1}=(3 / 2) k_{2}=3 k_{3}$ ) then the product distribution becomes $30 \%$ A, $44 \%$ P1, 22\% P2, and $4 \%$ $\mathrm{P} 3$. At the other extreme, to achieve 98\% P1 (dilactone), $k_{1} / k_{2}$ must approach 500 . If one defines a synthetically acceptable yield as $90 \%$, the demands on the system are greatly reduced, and $k_{1} / k_{2}$ need only be $\sim 50$.

Use of this analysis to comport the product distributions observed for BTF (Scheme 1) and now BTP (Scheme 2) requires assuming the selectivity factors: $(1)$ in acetonitrile and DMF are similar and (2) can be faithfully extrapolated to other temperatures. Speaking to the former, the $n$-heptylaminolysis of BTF in acetonitrile at $-15{ }^{\circ} \mathrm{C}$ shows $\sim 95 \%$ conversion to $\mathbf{1 b}$, comparable to the result obtained at $-41{ }^{\circ} \mathrm{C}$ in DMF (data not shown). The Arrhenius equation then allows selectivities at $-41{ }^{\circ} \mathrm{C}(233 \mathrm{~K})$ to be estimated, with some assumptions, from those obtained at $297 \mathrm{~K}$ (Table 2 and Table S3). Naturally, the 
Table 3. Experimentally and Computationally Derived Aminolysis Reactivity Indicators ${ }^{a}$

\begin{tabular}{|c|c|c|c|c|c|c|c|c|c|c|}
\hline entry & parameter & BTF & $1 b$ & $2 b b$ & BTP & $5 b$ & $6 \mathrm{bb}$ & BMF & BMP & 4 \\
\hline 1 & $\delta_{\mathrm{C}=\mathrm{O} \text { (lactone) }}(\mathrm{ppm})^{b}$ & $173.4^{c}$ & $174.2,173.9^{c}$ & $174.6^{c}$ & 167.3 & $168.0,167.9$ & 168.7 & $174.4^{d}$ & 168.3 & 168.7 \\
\hline 2 & $\nu_{\mathrm{C}=\mathrm{O} \text { (lactone) }}\left(\mathrm{cm}^{-1}\right)^{e}$ & 1821 & 1815 & 1808 & 1777 & 1773 & 1766 & 1812 & 1772 & 1774 \\
\hline 3 & $\mathrm{C}=\mathrm{O}(\AA)$ & $\begin{array}{l}1.188^{c_{,} f} \\
\quad[1.192(3)]^{d_{2} f}\end{array}$ & $\begin{array}{c}1.190,1.191^{c} \\
{[1.192(2),} \\
1.199(2)]^{g}\end{array}$ & $1.193^{c}$ & $\begin{array}{l}1.196^{f} \\
\quad[1.201(2)]^{f, g}\end{array}$ & $\begin{array}{c}1.198,1.199 \\
{[1.204(1)} \\
1.205(1)]^{g}\end{array}$ & 1.200 & 1.191 & 1.198 & $\begin{array}{l}1.199^{f} \\
\quad[1.197(4)]^{f, h}\end{array}$ \\
\hline 4 & $\mathrm{O}-\mathrm{C}(\mathrm{O})(\AA)$ & $\begin{array}{l}1.401^{c_{f} f} \\
\quad[1.388(3)]^{d_{2} f}\end{array}$ & $\begin{array}{c}1.394,1.401^{c} \\
{[1.379(19)} \\
1.396(19)]^{g}\end{array}$ & $1.394^{c}$ & $\begin{array}{l}1.383^{f} \\
{[1.379(17)]^{f, g}}\end{array}$ & $\begin{array}{c}1.378,1.379 \\
{[1.366(13)} \\
1.367(13)]^{g}\end{array}$ & 1.373 & 1.388 & 1.375 & $\begin{array}{l}1.375^{f} \\
\quad[1.366(4)]^{f, h}\end{array}$ \\
\hline 5 & $\pi^{*}$ occ. $(\mathrm{C}=\mathrm{O})^{i}$ & $0.180^{c_{f} f}$ & $0.183,0.187^{c}$ & $0.190^{c}$ & $0.181^{f}$ & $0.187,0.188$ & 0.193 & 0.192 & 0.189 & 0.196 \\
\hline 6 & $\omega(\mathrm{eV})^{j}$ & $1.73^{c}$ & $1.38^{c}$ & $1.10^{c}$ & 1.59 & 1.25 & 1.00 & 1.43 & 1.31 & 1.33 \\
\hline 7 & LUMO $(\mathrm{eV})$ & $-1.59^{c}$ & $-1.14^{c}$ & $-0.74^{c}$ & -1.41 & -0.99 & -0.65 & -1.20 & -0.98 & -0.99 \\
\hline 8 & $V_{\mathrm{C}}(\mathrm{au})^{k}$ & $-14.610^{f}$ & $-14.620,-14.626$ & -14.636 & $-14.621^{f}$ & $-14.636,-14.632$ & -14.646 & -14.630 & -14.634 & -14.630 \\
\hline
\end{tabular}

${ }^{a}$ Data in entries 1 and 2 are derived from experimental data obtained for the specifically indicated compounds. Data for the remaining entries are derived from quantum chemical calculations (at the B3LYP/6-311++G** level) unless specified otherwise, also on the specifically indicated compounds, except for $\mathbf{1} \mathbf{b}, \mathbf{2} \mathbf{b} \mathbf{b}, \mathbf{5 b}$, and $\mathbf{6} \mathbf{b} \mathbf{b}$ where the $n$-heptyl groups have been truncated to methyl groups. ${ }^{b_{13}} \mathrm{C}$ NMR chemical shifts for the lactone carbonyl carbons (in DMSO- $\left.d_{6}\right) .{ }^{c}$ Data taken from ref $10 .{ }^{d}$ Data taken from ref $11 .{ }^{e} \mathrm{IR}$ carbonyl energies from acetonitrile solution $(0.05-$ $0.3 \mathrm{M}) .{ }^{f}$ Average value for multiple carbonyl groups. ${ }^{g}$ From X-ray crystallographic data reported in this work for BTP, 1c, and 5a. ${ }^{h}$ From X-ray crystallographic data reported in ref 20. CSD code: DUJTIM. ${ }^{i}$ Occupancy of the lactone carbonyl $\pi^{*}$ orbital from NBO population analysis. ${ }^{j}$ Calculated global electrophilicity index. ${ }^{k}$ Electrostatic potential at nuclei (EPN).

selectivities increase at lower temperatures. Most importantly, the predicted product distributions match well with those found experimentally (Schemes 1 and 2). To wit, the nearly quantitative experimental conversion of BTF to $\mathbf{1 b}$ at low temperature is consistent with the $97 \%$ yield predicted on the basis of selectivity factors that exceed 100 (Table 2, entry 1). The much smaller selectivity factors associated with BTP aminolysis predict a marginally better than statistical product outcome; the experimental conversion to 5a (70\%) is only reasonably approximated by the $45 \%$ yield anticipated on the basis of its sequential reaction rates (Table 2, entry 2). This result suggests that the kinetic differences between the aminolysis of BTP and 5a in DMF are larger than those measured in acetonitrile. Based on the experimental yield of $\mathbf{5 a}$, one would expect a rate ratio $\left(k_{\mathrm{BTP}} / k_{5 \mathrm{a}}\right)$ of $\sim 10$ between BTP and $\mathbf{5 b}$ (see SI for expected outcomes based on rate ratios).

Origins of Sequential Aminolysis Reactivity: Electronic Effects. Even in the absence of a detailed aminolysis reaction mechanism (but assuming the same aminolysis mechanism for all of the compounds studied here), a Hammett-type analysis might predict sequential aminolysis reactivity for both the BTF and BTP systems given the substituent changes that occur at the central benzene ring along the reaction pathway. Each successive aminolysis reaction converts one $-\mathrm{OC}(=\mathrm{O}) \mathrm{CH}_{2}-$ substituent to a less electron withdrawing - $\mathrm{OH}$ substituent ${ }^{21}$ meta to the phenyl oxygen of a common lactone ring ( $-\mathrm{OH}: \sigma_{\mathrm{I}}=0.33, \sigma_{\mathrm{m}}=0.12$; - OAc: $\sigma_{\mathrm{I}}$ $\left.=0.42, \sigma_{\mathrm{m}}=0.39^{22}\right)$. The increasingly downfield lactone carbonyl ${ }^{13} \mathrm{C}$ NMR resonances (Table 3, entry 1) and lower $v_{\mathrm{C}=\mathrm{O}}$ wavenumbers (Figure $2 \mathrm{a}$ and Table 3, entry 2 ) from BTF $\rightarrow \mathbf{1 b} \rightarrow \mathbf{2 b b}$ (and BTP $\rightarrow \mathbf{5 b} \rightarrow \mathbf{6 b b}$ ) are consistent with this increase of electron density at the benzene ring based on spectroscopic trends known for meta- and para-substituted phenyl acetates. ${ }^{14 d, 23}$ It further follows that the rate of aminolysis should progressively decrease, again given similar behavior observed upon introduction of electron-donating substituents $\left(\mathrm{R}^{2}\right)$ to phenyl acetates of the general structure $p$ $\mathrm{R}^{2} \operatorname{PhOC}(=\mathrm{O}) \mathrm{R}^{1}{ }^{14 \mathrm{~b}, \mathrm{c}, \mathrm{e}, \mathrm{f}, 15 \mathrm{a}, 16,24}$

While consideration of substituent changes does predict the reactivity trend, it does not appear to fully capture the differences in aminolysis rate either between BTF and $\mathbf{1 b}$, or between BTF and BTP. In both series, BTF $\rightarrow \mathbf{1 b} \rightarrow \mathbf{2 b b} \rightarrow$
$3 \mathrm{bbb}$ and $\mathrm{BTP} \rightarrow 5 \mathrm{~b} \rightarrow 6 \mathrm{bb} \rightarrow 7 \mathrm{bbb}$, each aminolysis event reflects a $\Delta \sigma_{\mathrm{m}}$ of $\sim 0.3$ and a $\Delta \sigma_{\mathrm{I}}$ of $\sim 0.1(\sim \mathrm{OAc} \rightarrow \mathrm{OH})$. For the aminolysis of $p$-substituted phenyl acetates in $\mathrm{CH}_{3} \mathrm{CN}$ (where $\rho=3.3$, a value derived using $\log k / k_{0}=\sigma_{\mathrm{p}} \rho$ from experimental rate data $\left.{ }^{14 \mathrm{~b}}\right)$, a $\Delta \sigma_{\mathrm{p}}$ of $\sim 0.3$ constitutes a $\sim 10$-fold rate change (or $k_{1} / k_{2} \sim 10$ ). Not only does the BTF aminolysis sequence not subscribe to a linear rate progression, $k_{\mathrm{lac}(\mathrm{BTF})} /$ $k_{\mathrm{lac}(\mathbf{1 b})}$ is $\sim 50$. That $k_{\mathrm{lac}(\mathrm{BTF})}: k_{\mathrm{lac}(\mathrm{BTP})}$ equals 180:1.0 (vide supra) also suggests that BTF, and perhaps $\mathbf{1 b}$, benefit from a boost in reactivity beyond statistical and electronic considerations. Worth noting, however, is that these two factors (steric effects notwithstanding) may sufficiently describe the rate differences observed along BTP $\rightarrow 5 \mathrm{~b} \rightarrow 6 \mathrm{bb} \rightarrow 7 \mathrm{bbb}$.

Nonetheless, as described in our earlier work, a variety of computationally (DFT) derived reactivity descriptors nicely predict, on the basis of electronic structure, an aminolysis rate gradient as BTF $>\mathbf{1} \mathbf{b}>\mathbf{2} \mathbf{b} \mathbf{b}$. The approach is extended here to BTP, $\mathbf{5 b}, \mathbf{6 b b}$, and selected model compounds (Table 3 and Tables S4 and S5). Low energy geometries for the new molecules have been obtained in the gas phase at the B3LYP/6$311++\mathrm{G}^{* *}$ level, and frequency calculations have been performed to assign the structures as minima (details, including structural coordinates, are provided in the SI).

An increase in the lactone $\mathrm{C}=\mathrm{O}$ (entry 3 ) and decrease in the $\mathrm{O}-\mathrm{C}(\mathrm{O})$ (entry 4) bond lengths are readily apparent along $\mathrm{BTF} \rightarrow \mathbf{1 b} \rightarrow \mathbf{2 b b}$ and BTP $\rightarrow 5 \mathrm{~b} \rightarrow \mathbf{6 b b}$ (consistent with the IR $\mathrm{C}=\mathrm{O}$ stretch data, and mirrored in X-ray crystallographic data, vide infra). This data together with entries $1-2$ and the increasing lactone carbonyl $\pi^{*}$ occupancy values ${ }^{25}$ (NBO population analysis, ${ }^{26}$ entry 5) from BTF $\rightarrow 2$ and BTP $\rightarrow 6$ are consistent with greater delocalization of the phenolic oxygen electrons into the lactone carbonyl and decreased carbonyl electrophilicity. The reactivity trend is also mirrored by decreasing global electrophilicity values ${ }^{27}(\omega$, entry 6$)$, increasing LUMO energies (entry 7), and decreasing electrostatic potentials at nuclei $(\mathrm{EPN})^{28}$ (entry 8$)$. The latter parameter was previously indicated to be the best electrostatic predictor of aminolysis rates in model phenyl acetates by Galabov et al. ${ }^{14 \mathrm{~b}}$

Mostly all of these computationally determined reactivity descriptors speak to the stepwise decrease in reactivity within a series (i.e., BTF and BTP) while also supporting the increased 
reactivity of the BTF series as compared to the BTP series. The same experimental and theoretical reactivity descriptors do well to predict the increased aminolysis rate of model compound BMF versus BMP or 4 . We were not, however, able to more quantitatively correlate the experimentally determined rate constants to the computed reactivity parameters in these systems.

Structural Confirmation and Reactivity Clues from Xray Crystallography. Crystals suitable for X-ray diffraction could be obtained for BTF, 1c, BTP, and 5a (the crystal structure of BTF has been previously reported; ${ }^{11}$ CSD code: MUDBIX); the solved structures are shown in Figure 3 and full
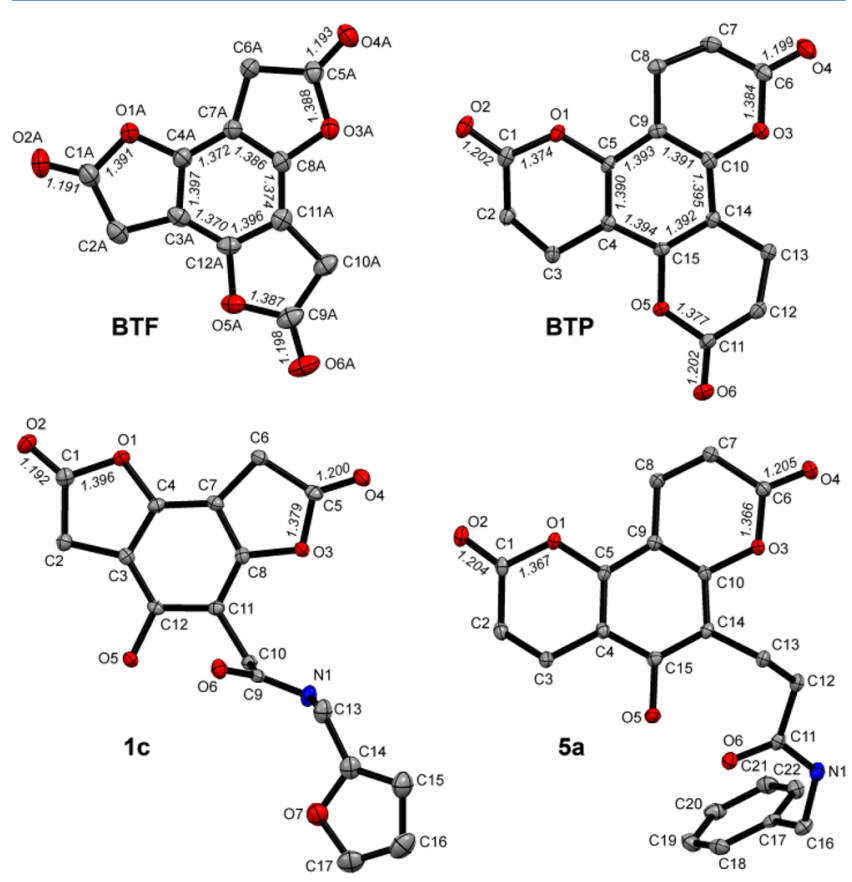

Figure 3. X-ray crystal structures of BTF, BTP, 1c, and 5a. Selected bond distances are shown in $\AA$. Hydrogen atoms and solvent molecules have been omitted for clarity. Only one of the crystallographically independent molecules is shown for BTF. Thermal ellipsoids are drawn at the $50 \%$ probability level. Atom colors: blue = nitrogen; gray $=$ carbon; red $=$ oxygen. See the SI for additional plots and full data analysis.

crystallographic details can be found in the SI (Table S9). When comparing diagnostic bond lengths of the benzofuranones (BTF and 1c) to the benzopyranones (BTP and 5a) (Figure 3 and Table 3, entries 3 and 4), there is good agreement with computational data and the trends that emerge speak to differences in reactivity. The five-membered ring lactone structures are characterized by both shorter $\mathrm{C}=\mathrm{O}$ (lactone) bond lengths (BTF average 1.194 Å, 1c average 1.196 $\AA$ ) and longer $\mathbf{O}-\mathbf{C}=\mathrm{O}$ bond lengths (BTF average $1.388 \AA$, 1c average $1.388 \AA$ ) as compared to the six-membered ring lactones (average $\mathrm{C}=\mathrm{O}$ : BTP, $1.201 \AA$ 作 5a, $1.205 \AA$; average O-C=O: BTP, $1.378 \AA$; 5a, $1.367 \AA$ ). The average $\mathrm{C}=\mathrm{O}$ bond length also increases upon ring opening in each family (e.g., from BTF to 1c; from BTP to 5a). Of additional note, the lactone rings of BTF and 1c are essentially coplanar with the central aromatic ring, while those of BTP and 5a are significantly puckered. That this geometry difference could influence the extent of $\pi$-delocalization of the phenolic oxygen lone pair into the central benzene ring in each case is reflected in the shorter $\mathrm{O}-\mathrm{C}_{\text {aryl }}$ bond length for BTF versus BTP (average O-C $\mathrm{C}_{\text {aryl }}$ : BTF, $1.388 \AA$ A; BTP, $1.402 \AA$ ). Overall, it is a decrease in the carbonyl and $\mathrm{O}-\mathrm{C}_{\text {aryl }}$ bond lengths and increase in the $\mathrm{O}-\mathrm{C}=\mathrm{O}$ bond lengths that parallels increased lactone aminolysis reactivity.

Also critically evident from the X-ray structural data are $\mathrm{C}-\mathrm{C}$ bond length distortions imposed on the central benzene ring of BTF, but not BTP, as a consequence of the fused lactones. BTF reveals a bond length alternation $(\Delta R)^{29}$ of $0.024 \AA$ (0.021 $\AA$ averaged over two crystallographically independent molecules), comparable to tricyclobutabenzene, ${ }^{30}$ where the benzene $\mathrm{C}-\mathrm{C}$ bonds contained within the five-membered lactone rings are longer than those between the fused rings. BTP shows a negligible $\Delta R$ of $0.003 \AA$ (Figure 3). The $\Delta R$ values are reproduced excellently by DFT calculations (see Table S6). The phenomenon of angle-strain induced bond alternation in especially 3 -fold symmetric benzenoid systems is well-documented (and oftentimes referred to as the MillsNixon effect). ${ }^{29-31}$ Consequently, it is reasonable to consider whether the deviations in core benzene structure between BTF, BTP, and their ring-opened aminolysis products speak to differences in strain and therefore reactivity (vide infra).

Origins of Sequential Aminolysis Reactivity: Strain. In addition to the bond length alternation evident within the central benzene ring of BTF, the IR data shown in Figure 2/ Table 3 is compelling with respect to diagnosing the unusual strain associated with this molecule. Ring strain, especially in cyclic lactones, has long been evaluated against the $\mathrm{C}=\mathrm{O}$ stretch energy. Take, for example, the IR data (in $\left.\mathrm{CCl}_{4}\right)^{32}$ for the classic molecular series of four-membered $\beta$-propiolactone $\left(\nu_{\mathrm{C}=\mathrm{O}}=1818 \mathrm{~cm}^{-1}\right)$, five-membered $\gamma$-butyrolactone $\left(\nu_{\mathrm{C}=\mathrm{O}}=\right.$ $\left.1775 \mathrm{~cm}^{-1}\right)$, and six-membered $\delta$-valerolactone $\left(\nu_{\mathrm{C}=\mathrm{O}}=1740\right.$ $\mathrm{cm}^{-1}$ ). The carbonyl stretching energy (in $\mathrm{CH}_{3} \mathrm{CN}$ ) for BTF $\left(\nu_{\mathrm{C}=\mathrm{O}}=1821 \mathrm{~cm}^{-1}\right)$ exceeds that of $\beta$-propiolactone. Historical studies remind us to treat this IR data cautiously. To wit, the experimental (calorimetric) ring strain enthalpy ${ }^{33}$ does not follow the IR trend as $\beta$-propiolactone $(23 \mathrm{kcal}$ $\left.\mathrm{mol}^{-1}\right)>\delta$-valerolactone $\left(9.5 \mathrm{kcal} \mathrm{mol}^{-1}\right)>\gamma$-butyrolactone $\left(7.7 \mathrm{kcal} \mathrm{mol}^{-1}\right)$, a result of the interplay between angle/ torsional strain and stereoelectronic effects. The strain trend is mirrored in associated reaction rates and reversible polymerization capability. ${ }^{34}$

A more relevant approach is to look at bicyclic benzolactones, where BMF (Chart 1) has been estimated to be (on the basis of solution-phase hydrolysis studies) $\sim 1.2 \mathrm{kcal}$ mol $^{-1}$ more strained than BMP. ${ }^{17}$ The data suggests that the $\nu_{\mathrm{C}=\mathrm{O}}$ values may follow the strain trend for these fused systems, and therefore be a reasonable predictor of, in this case, relative aminolysis reactivity. So, is BTF more "strained" than BTP, and is strain expected to be relieved (at least with respect to the heterocyclic core) upon aminolysis? To approach quantifying strain effects we performed a series of theoretical (DFT; B3LYP/6-31+G**) calculations to estimate the "strain energy" of the model heterocycles (Chart 1) that represent substructures of the species formed along the aminolysis pathways of both BTF and BTP. The results are given in Table 4 and relevant data is provided in Tables S7 and S8. To evaluate strain, theoretical heats of formation at $298 \mathrm{~K}$ $\left(\Delta_{\mathrm{f}} \mathrm{H}_{\text {gas-calcd }}^{\circ}\right)$-determined from appropriate homodesmotic reactions $^{37}$ (see the SI for the reactions used) involving experimental $\Delta_{\mathrm{f}} H_{\text {gas }}^{\circ}$ values-were compared to values determined for hypothetical "unstrained" molecules (through strain-free group additivity values). That the approach is sound 
Table 4. Enthalpies of Formation for Parent Benzofuran Heterocycles from Homodesmotic Reactions and Estimation of Strain Enthalpies

\begin{tabular}{|c|c|c|c|c|c|c|}
\hline & BTF & BTP & BDF & BDP & BMF & BMP \\
\hline$\Delta_{\mathrm{f}} H_{\text {gas-expt }}^{\circ}$ & & & & & $-51.1^{b}$ & $-59.2^{c}$ \\
\hline$\Delta_{\mathrm{f}} H_{\text {gas-calcd }}^{\circ}{ }^{\circ}$ & -190.3 & -214.1 & -121.3 & -136.6 & -51.7 & -58.3 \\
\hline$\Delta_{\mathrm{f}} H_{\text {gas-GAV }}^{\circ}$ & -218.1 & -231.3 & -138.8 & -147.6 & -59.5 & -63.9 \\
\hline$\Delta_{\mathrm{f}} H_{\text {gas-calcd }}^{\circ}-\Delta_{\mathrm{f}} H_{\text {gas-GAV }}^{\circ}$ ("strain enthalpy") & 27.9 & 17.3 & 17.5 & 11.0 & 8.4 & 4.7 \\
\hline strain loss $(\mathrm{BT} \rightarrow \mathrm{BD})$ & 10.4 & 6.3 & & & & \\
\hline strain loss $(\mathrm{BD} \rightarrow \mathrm{BM})$ & & & 9.1 & 6.3 & & \\
\hline
\end{tabular}

${ }^{a}$ All enthalpies or heats of formation have been determined in the gas phase at $298 \mathrm{~K}$. All values in the table are in $\mathrm{kcal}$ mol ${ }^{-1}$. GAV $=\mathrm{strain}^{-\mathrm{free}}$ group additivity value. ${ }^{b} \operatorname{Ref} 35 .{ }^{c}$ Ref $36 .{ }^{d}$ Determined from up to two different homodesmotic reactions and known $\Delta_{\mathrm{f}} H^{\circ}$ gas-expt values (see the SI for details). ${ }^{e}$ Determined from strain-free group additivity values (see the SI for details).

comes, in part, through the excellent agreement (within 2\%) between the experimental and theoretical $\Delta_{\mathrm{f}} H^{\circ}$ gas values for BMF and BDF (Table 4). The trends in strain enthalpy values are consistent with the overall aminolysis rate behavior found for the individual BTF and BTP series. That is, $k_{\mathrm{lac}(\mathrm{BTF})}>$ $k_{\mathrm{lac}(\mathrm{BDF})}>k_{\mathrm{lac}(\mathrm{BTP})} \geq k_{\mathrm{lac}(\mathrm{BDP})}$ (on a per lactone basis) as strain (on a per lactone basis) decreases as BTF $>$ BDF $>$ BTP $\geq$ BDP. Moreover, the strain loss difference in $\mathrm{BT} \rightarrow \mathrm{BD}$ between BTF and BTP $\left(10.4-6.3=4.1 \mathrm{kcal} \mathrm{mol}^{-1}\right)$ is, admittedly fortuitously, in the ballpark of the activation energy difference $\left(\sim 3 \mathrm{kcal} \mathrm{mol}^{-1}\right)$ that corresponds to the 180 -fold difference in experimental monoaminolysis rate between the compounds. More interesting is that the change in ring strain along the hypothetical reaction pathway $\mathrm{BTF} \rightarrow$ BDF $\rightarrow$ BMF is not constant; the strain loss in the first step $\left(10.4 \mathrm{kcal} \mathrm{mol}^{-1}\right)$ is greater than the second $\left(9.1 \mathrm{kcal} \mathrm{mol}^{-1}\right)$. Such is not the case for BTP $\rightarrow$ BDP $\rightarrow$ BMP pathway where the same magnitude of strain release $\left(6.3 \mathrm{kcal} \mathrm{mol}^{-1}\right)$ is found for both steps. The "gradient" observed in the BTF series is a novel observation among reactive small-molecule systems and may help to rationalize the unusual aminolysis reactivity of the parent molecule. Future work could consider theoretically modeling the specific consecutive aminolysis reactions where the differences in transition state energies (e.g., for the putative tetrahedral intermediates) could alternatively link strain and reactivity.

\section{CONCLUSIONS}

When the unexpectedly efficient sequential aminolysis capability of benzotrifuranone (BTF) was identified several years ago, ${ }^{10}$ it both highlighted the exclusivity of cyanuric chloride (CC) with respect to this chemical behavior and offered a new structural basis upon which to consider achieving selective and stepwise transformations. In this work, the origins of BTF's sequential reactivity profile have been more comprehensively understood through comparison of the trilactone to structurally related molecules and a combination of kinetics measurements, $\mathrm{X}$-ray crystallography, and computational analysis. Revealed is that the increasingly slowed aminolysis rates as BTF $\rightarrow 1 \rightarrow 2$ $\rightarrow 3$, and the extremely fast reaction of BTF with amines (versus BTP but also conventional "activated" esters), is best rationalized through a synergy of ring strain and inductive effects. More compellingly, while ring strain is relieved upon the sequential aminolysis of both BTF and BTP, it is only in the former that a ring strain gradient is established that amplifies stepwise aminolysis rate differences and contributes to enhanced selectivity.

Singular strain release events are a powerful and much appreciated way to promote chemical reactions. ${ }^{12}$ Beyond this, and exposed fortuitously by BTF, one could consider marrying electronic and strain effects in new ways to establish useful kinetic gradients and/or unprecedented levels of chemoselectivity. Along these lines, and toward the design of new molecular examples, it is exciting to see how well modern day computational methods can predict reactivity trends on the basis of readily accessible structural/electronic parameters. In the short term we are exploring whether ring strain as it is diagnosed by the so-called Mills-Nixon effect is a useful starting point for identifying such new scaffolds for one-pot molecular multifunctionalization schemes.

\section{EXPERIMENTAL SECTION}

General Information. DMF was degassed in $20 \mathrm{~L}$ drums and passed through two sequential purification columns (molecular sieves) under a positive argon atmosphere. Thin layer chromatography (TLC) was performed on aluminum backed $\mathrm{SiO}_{2}-60 \mathrm{~F} 254$ TLC plates with visualization via UV light and either ninhydrin or $\mathrm{KMnO}_{4}$ stains; products stained different colors based on the number of lactone rings present. Flash column chromatography was performed using $\mathrm{SiO}_{2}-60$ 230-400 mesh silica gel and mobile phases as indicated within procedures. ${ }^{1} \mathrm{H}$ NMR and ${ }^{13} \mathrm{C}$ NMR were recorded on spectrometers operating at 300 or $500 \mathrm{MHz}$ for ${ }^{1} \mathrm{H}$ and at 75 or $126 \mathrm{MHz}$ for ${ }^{13} \mathrm{C}$ as specified. Chemical shifts $(\delta)$ are given in parts per million $(\mathrm{ppm})$ relative to residual protonated solvent (DMSO- $d_{6}: \delta_{\mathrm{H}} 2.50 \mathrm{ppm}, \delta_{\mathrm{C}}$ $\left.39.50 \mathrm{ppm} ; \mathrm{CDCl}_{3}: \delta_{\mathrm{H}} 7.24 \mathrm{ppm}, \delta_{\mathrm{C}} 77.0 \mathrm{ppm}\right)$. Abbreviations used are s (singlet), d (doublet), t (triplet), q (quartet), $\mathrm{p}$ (pentet), and $\mathrm{m}$ (multiplet). MS spectra (HRMS) were acquired on a $4.7 \mathrm{~T}$ Fourier Transform Ion Cyclone Resonance mass spectrometer. EI-MS spectra were recorded on a single quadrupole spectrometer. Electrospray ionization (ESI) or direct analysis in real time (DART) high-resolution mass spectra (HRMS) were recorded on an ESI-TOF instrument, operating in positive or negative ion mode as stated, with methanol as the carrier solvent for ESI experiments. The following compounds were prepared based on our earlier literature procedures and provided ${ }^{1} \mathrm{H}$ NMR data consistent with the literature: 1 c, ${ }^{10}$ triisopropyl $3,3^{\prime}, 3^{\prime \prime}$ (2,4,6-trihydroxybenzene-1,3,5-triyl)tripropionate, ${ }^{13}$ BMF (2-coumaranone), ${ }^{11}$ and BTF. ${ }^{11}$ BMP (3,4-dihydrocoumarin) was obtained commercially and used without further purification.

Starting Material Synthesis. 3,4,7,8,11,12-Hexahydro- $2 \mathrm{H}-$ dipyrano[2,3-f:2', 3'-h]chromene-2,6,10-trione (BTP). To a solution of triisopropyl 3,3',3'-(2,4,6-trihydroxybenzene-1,3,5-triyl)tripropionate $^{13}(0.40 \mathrm{~g}, 0.87 \mathrm{mmol})$ in toluene $(40 \mathrm{~mL})$ was slowly added trifluoroacetic acid $(2 \mathrm{~mL})$ under argon. The solution was then heated at $80{ }^{\circ} \mathrm{C}$ for $2 \mathrm{~h}$. The orange solution was concentrated under vacuo to give BTP $(0.25 \mathrm{~g}$, quant) as an off-white solid with no further purification required: ${ }^{1} \mathrm{H}$ NMR $\left(500 \mathrm{MHz}, \mathrm{DMSO}-d_{6}\right): \delta 2.94(\mathrm{t}, J=$ $7.3 \mathrm{~Hz}, 6 \mathrm{H}), 2.79(\mathrm{t}, J=7.3 \mathrm{~Hz}, 6 \mathrm{H}) .{ }^{13} \mathrm{C}$ NMR $(126 \mathrm{MHz}$, DMSO$\left.d_{6}\right) \delta 167.3,147.4,106.9,27.6,16.9$. HRMS (EI) calcd for $\mathrm{C}_{15} \mathrm{H}_{12} \mathrm{O}_{6}$ $[\mathrm{M}]^{+}:$288.0634, found: 288.0659. IR $\left(\mathrm{CH}_{3} \mathrm{CN}\right): \nu_{\mathrm{C}=\mathrm{O}} 1777 \mathrm{~cm}^{-1}$.

Benzene-1,3,5-triyl Triacetate (4). Phloroglucinol triacetate was prepared using a general literature approach (representative procedure $\left.{ }^{38}\right)$. NMR data, recorded in DMSO- $d_{6}$, is consistent with 
the structure of the known compound. ${ }^{1} \mathrm{H}$ NMR (500 MHz, DMSO$\left.d_{6}\right): \delta 6.94(\mathrm{~s}, 3 \mathrm{H}), 2.26(\mathrm{~s}, 9 \mathrm{H}) .{ }^{13} \mathrm{C}$ NMR $\left(126 \mathrm{MHz}, \mathrm{DMSO}-d_{6}\right) \delta$ 168.7, 150.9, 113.5, 20.7. IR $\left(\mathrm{CH}_{3} \mathrm{CN}\right): \nu_{\mathrm{C}=\mathrm{O}} 1774 \mathrm{~cm}^{-1}$.

Preparation of Representative/Model Compounds via Aminolysis. N-Benzyl-3-(5-hydroxy-2,8-dioxo-2,3,4,8,9,10hexahydropyrano[2,3-f]chromen-6-yl)propanamide (5a). To a solution of BTP $(50.0 \mathrm{mg}, 173 \mu \mathrm{mol})$ in DMF $(5 \mathrm{~mL})$, cooled to $-41{ }^{\circ} \mathrm{C}$, was dropwise added a benzylamine (a) solution $(346 \mu \mathrm{L}$ of a $0.503 \mathrm{M}$ solution in DMF, $174 \mu \mathrm{mol}$ ). TLC analysis showed modest change after $4 \mathrm{~h}$, so the reaction was allowed to warm to rt overnight, diluted with EtOAc, and washed sequentially with $0.1 \mathrm{~N} \mathrm{HCl}, \mathrm{DI} \mathrm{H}_{2} \mathrm{O}$ $(\times 3)$, then brine. The organics were dried over $\mathrm{Na}_{2} \mathrm{SO}_{4}$ and volatiles were removed in vacuo. Compound 5a was isolated via column chromatography (acetone gradient in DCM; $R_{\mathrm{f}} \sim 0.5$ in $5 \%$ acetone in DCM) to yield a colorless oil (52.0 mg, 76\% yield). ${ }^{1} \mathrm{H}$ NMR (500 $\left.\mathrm{MHz}, \mathrm{DMSO}-d_{6}\right) \delta 9.69(\mathrm{~s}, 1 \mathrm{H}), 8.60(\mathrm{t}, J=5.8 \mathrm{~Hz}, 1 \mathrm{H}), 7.30(\mathrm{~m}$, $2 \mathrm{H}), 7.22(\mathrm{~m}, 3 \mathrm{H}), 4.28(\mathrm{~d}, J=5.5 \mathrm{~Hz}, 2 \mathrm{H}), 2.89-2.70(\mathrm{~m}, 12 \mathrm{H}) .{ }^{13} \mathrm{C}$ NMR $\left(126 \mathrm{MHz}, \mathrm{DMSO}-d_{6}\right) \delta 173.0,168.0,167.9,151.1,149.1$, $147.1,139.0,128.3,127.2,126.8,112.2,107.1,102.6,42.3,34.5,28.0$, 27.9, 18.3, 17.6, 16.8. HRMS (ESI) calcd $(m / z)$ for $\mathrm{C}_{22} \mathrm{H}_{21} \mathrm{NNaO}_{6}[\mathrm{M}$ $+\mathrm{Na}]^{+}$418.1261, found 418.1272 .

N-Heptyl-3-(5-hydroxy-2,8-dioxo-2,3,4,8,9, 10-hexahydropyrano[2,3-f]chromen-6-yl)propanamide (5b). To a solution of BTP (49.3 $\mathrm{mg}, 171 \mu \mathrm{mol})$ in DMF $(3 \mathrm{~mL})$, cooled to $-41{ }^{\circ} \mathrm{C}$, was dropwise added an $n$-heptylamine (b) solution $(340 \mu \mathrm{L}$ of a $0.503 \mathrm{M}$ solution in DMF, $171 \mu \mathrm{mol}$ ). The reaction mixture was allowed to stir for $6 \mathrm{~h}$ and then warmed to $\mathrm{rt}$ overnight, diluted with EtOAc, and washed sequentially with $0.1 \mathrm{~N} \mathrm{HCl}, \mathrm{DI} \mathrm{H}_{2} \mathrm{O}(\times 3)$, then brine. Compound $\mathbf{5 b}$ was isolated after column chromatography (gradient, 0-95\% EtOAc in hexanes; $R_{\mathrm{f}} \sim 0.5$ in 1:1 hexanes/EtOAc) yielding an amorphous solid (44 mg, 71\% yield). ${ }^{1} \mathrm{H}$ NMR (500 MHz, DMSO- $\left.d_{6}\right) \delta 9.89(\mathrm{~s}, 1 \mathrm{H})$, $8.10(\mathrm{t}, J=5.5 \mathrm{~Hz}, 1 \mathrm{H}), 3.03(\mathrm{q}, J=6.8 \mathrm{~Hz}, 2 \mathrm{H}), 2.85(\mathrm{~m}, 6 \mathrm{H}), 2.73$ $(\mathrm{m}, 6 \mathrm{H}), 2.44(\mathrm{t}, J=6.7 \mathrm{~Hz}, 2 \mathrm{H}), 1.36(\mathrm{~m}, 2 \mathrm{H}), 1.21(\mathrm{~m}, 6 \mathrm{H}), 0.85(\mathrm{t}$, $J=6.8 \mathrm{~Hz}, 3 \mathrm{H}) .{ }^{13} \mathrm{C}$ NMR $\left(126 \mathrm{MHz}\right.$, DMSO- $\left.d_{6}\right) \delta 173.1,168.0$, $167.9,151.2,149.1,147.1,112.3,107.1,102.6,38.8,34.4,31.2,28.8$, 28.3, 28.1, 27.9, 26.3, 22.0, 18.1, 17.6, 16.8, 13.9. HRMS (ESI) calcd $(\mathrm{m} / z)$ for $\mathrm{C}_{22} \mathrm{H}_{29} \mathrm{NNaO}_{6}[\mathrm{M}+\mathrm{Na}]^{+} 426.1887$, found 426.1895. IR $\left(\mathrm{CH}_{3} \mathrm{CN}\right): \nu_{\mathrm{C}}=\mathrm{O}$ (lactone) $1773 \mathrm{~cm}^{-1}$ (two absorptions, unresolved).

3,3'-(5,7-Dihydroxy-2-oxochroman-6,8-diyl)bis( $N$-benzylpropanamide) (6aa). To a solution of BTP $(50.0 \mathrm{mg}, 174 \mu \mathrm{mol})$ in DMF $(3 \mathrm{~mL})$, cooled to $-41{ }^{\circ} \mathrm{C}$, was dropwise added a benzylamine (a) solution ( $800.4 \mu \mathrm{L}$ of a $0.503 \mathrm{M}$ solution in DMF, $400 \mu \mathrm{mol})$. The reaction mixture was allowed to stir for $12 \mathrm{~h}$ before warming to rt; the reaction was worked up similar to 5 a. Compound $\mathbf{6 a a}$ was isolated via column chromatography (acetone into DCM gradient, $R_{\mathrm{f}} \sim 0.5$ in $10 \%$ acetone in DCM) yielding an amorphous solid ( $53 \mathrm{mg}, 61 \%$ yield). ${ }^{1} \mathrm{H}$ NMR $\left(300 \mathrm{MHz}, \mathrm{CDCl}_{3}\right) \delta 9.44(\mathrm{~s}, 1 \mathrm{H}), 9.32(\mathrm{~s}, 1 \mathrm{H}), 7.27-7.21(\mathrm{~m}$, $6 \mathrm{H}), 7.14-7.07(\mathrm{~m}, 4 \mathrm{H}), 6.06(\mathrm{t}, J=5.6 \mathrm{~Hz}, 1 \mathrm{H}), 5.98(\mathrm{t}, J=5.5 \mathrm{~Hz}$, $1 \mathrm{H}), 4.36(\mathrm{~d}, J=5.7 \mathrm{~Hz}, 2 \mathrm{H}), 4.34(\mathrm{~d}, J=5.8 \mathrm{~Hz}, 2 \mathrm{H}), 2.95-2.86(\mathrm{~m}$, $6 \mathrm{H}), 2.68-2.61(\mathrm{~m}, 6 \mathrm{H}) .{ }^{13} \mathrm{C} \mathrm{NMR}\left(\mathrm{CDCl}_{3}\right) \delta 175.2,174.9,169.6$, 153.4, 151.6, 149.7, 137.4, 137.3, 128.8, 128.7, 127.7 (3 peaks), 113.3, $107.9,103.5,44.0,35.8,35.3,29.2,18.6,17.8,17.8$ (missing two peaks). HRMS (ESI) calcd $(m / z)$ for $\mathrm{C}_{29} \mathrm{H}_{30} \mathrm{~N}_{2} \mathrm{NaO}_{6}\left[\mathrm{M}+\mathrm{Na}^{+}\right]$ 525.1996 , found 525.2011 .

3,3'-(5,7-Dihydroxy-2-oxochroman-6,8-diyl)bis(N-heptylpropanamide) (6bb). BTP $(50.0 \mathrm{mg}, 173 \mu \mathrm{mol})$ was dissolved in DMF and cooled to $0{ }^{\circ} \mathrm{C}$ in an ice bath before dropwise addition of an $n$ heptylamine (b) solution $(51.6 \mu \mathrm{L}, 348 \mu \mathrm{mol})$. The reaction was allowed to stir overnight, slowly warming to rt. The reaction was worked up similar to $\mathbf{5 b}$. Compound $\mathbf{6} \mathbf{b} \mathbf{b}$ was isolated via column chromatography (3\%-15\% EtOAc in DCM) yielding an amorphous solid (55 mg, 61\% yield). ${ }^{1} \mathrm{H}$ NMR (500 MHz, DMSO- $\left.d_{6}\right) \delta 9.52(\mathrm{~s}$, $1 \mathrm{H}), 9.30(\mathrm{~s}, 1 \mathrm{H}), 8.11(\mathrm{t}, J=5.7 \mathrm{~Hz}, 1 \mathrm{H}), 8.04(\mathrm{t}, J=5.5 \mathrm{~Hz}, 1 \mathrm{H})$, $3.02(\mathrm{~m}, 4 \mathrm{H}), 2.77(\mathrm{t}, J=7.2 \mathrm{~Hz}, 2 \mathrm{H}), 2.72-2.65(\mathrm{~m}, 6 \mathrm{H}), 2.39(\mathrm{~m}, 4$ $\mathrm{H}), 1.35(\mathrm{~m}, 4 \mathrm{H}), 1.28-1.14(\mathrm{~m}, 16 \mathrm{H}), 0.84(\mathrm{~m}, 6 \mathrm{H}) .{ }^{13} \mathrm{C}$ NMR $(126$ MHz, DMSO- $\left.d_{6}\right) \delta 173.9,173.2,168.7,152.6,150.6,148.9,112.8$, 108.0, 102.6, 38.8, 38.7, 34.9, 34.6, 31.2, 28.9, 28.9, 28.5, 28.4, 26.3, 22.0, 18.5, 18.2, 17.6, 13.9 (missing five peaks). HRMS (ESI) calcd $(m / z)$ for $\mathrm{C}_{29} \mathrm{H}_{47} \mathrm{~N}_{2} \mathrm{O}_{6}[\mathrm{M}+\mathrm{H}]^{+}$519.3429, found 519.3439. IR $\left(\mathrm{CH}_{3} \mathrm{CN}\right): \nu_{\mathrm{C}=\mathrm{O}(\text { lactone })} 1766 \mathrm{~cm}^{-1}$.
3,3',3"-(2,4,6-Trihydroxybenzene-1,3,5-triyl)tris(N-heptylpropanamide) (7bbb). BTP $(25.3 \mathrm{mg}, 87.8 \mu \mathrm{mol})$ was dissolved into $\mathrm{CH}_{3} \mathrm{CN}(10 \mathrm{~mL})$ and then $n$-heptylamine $\mathbf{b}(235 \mu \mathrm{L}, 1.58 \mathrm{mmol})$ was added dropwise. The reaction was allowed to proceed for $20 \mathrm{~h}$ before pouring into EtOAc and washing with $1 \mathrm{~N} \mathrm{HCl}, \mathrm{DI} \mathrm{H}_{2} \mathrm{O}$, and brine. Organics were dried over $\mathrm{Na}_{2} \mathrm{SO}_{4}$ and volatiles were removed in vacuo. The crude was purified via column chromatography (gradient, $0-100 \%$ EtOAc in hexanes) yielding $7 \mathbf{b b b}$ an amorphous solid (54 mg, 97\% yield). ${ }^{1} \mathrm{H}$ NMR ( $\left.500 \mathrm{MHz}, \mathrm{DMSO}-d_{6}\right) \delta 9.05(\mathrm{~s}, 3 \mathrm{H}), 8.07$ $(\mathrm{t}, J=5.7 \mathrm{~Hz}, 3 \mathrm{H}), 3.01(\mathrm{q}, J=6.6 \mathrm{~Hz}, 6 \mathrm{H}), 2.62(\mathrm{t}, J=6.4 \mathrm{~Hz}, 6 \mathrm{H})$, $2.38(\mathrm{t}, J=6.3 \mathrm{~Hz}, 6 \mathrm{H}), 1.34(\mathrm{p}, J=7.2 \mathrm{~Hz}, 6 \mathrm{H}), 1.27-1.15(\mathrm{~m}, 24 \mathrm{H})$, $0.84(\mathrm{t}, J=6.9 \mathrm{~Hz}, 9 \mathrm{H}) .{ }^{13} \mathrm{C}$ NMR $\left(126 \mathrm{MHz}, \mathrm{DMSO}-d_{6}\right) \delta 174.2$, 152.1, 108.2, 38.8, 34.9, 31.2, 28.9, 28.4, 26.3, 22.0, 18.5, 13.9. HRMS (ESI) calcd for $\mathrm{C}_{36} \mathrm{H}_{63} \mathrm{~N}_{3} \mathrm{NaO}_{6}[\mathrm{M}+\mathrm{Na}]^{+}$656.4609; found 656.4579 .

N-Heptyl-2-(2-hydroxyphenyl)acetamide (n-Heptyl Aminolysis Product of BMF). To a solution of 2-coumaranone $(0.100 \mathrm{~g}, 0.746$ $\mathrm{mmol})$ in dry $\mathrm{MeCN}$ at $\mathrm{rt}$ under an argon atmosphere was added $n$ heptylamine $(220 \mu \mathrm{L}, 1.49 \mathrm{mmol})$ and the reaction was stirred for 16 h. The mixture was then dissolved in $\mathrm{CHCl}_{3}(50 \mathrm{~mL})$ and washed with $1 \mathrm{M} \mathrm{HCl}(25 \mathrm{~mL})$, water $(25 \mathrm{~mL})$, and brine $(25 \mathrm{~mL})$. The organic phase was dried over $\mathrm{Na}_{2} \mathrm{SO}_{4}$, concentrated, and purified by flash chromatography using EtOAc/hexanes $30 \%$ to afford the product (0.699 mmol, 94\% yield) as a white solid: ${ }^{1} \mathrm{H}$ NMR $(500 \mathrm{MHz}$, DMSO- $\left.d_{6}\right) \delta 9.75(\mathrm{~s}, 1 \mathrm{H}), 7.97(\mathrm{t}, J=5.2 \mathrm{~Hz}, 1 \mathrm{H}), 7.08-7.01(\mathrm{~m}$, $2 \mathrm{H}), 6.78(\mathrm{~d}, J=8.4 \mathrm{~Hz}, 1 \mathrm{H}), 6.72(\mathrm{t}, J=7.4 \mathrm{~Hz}, 1 \mathrm{H}), 3.38(\mathrm{~s}, 2 \mathrm{H})$, $3.04(\mathrm{q}, J=6.8 \mathrm{~Hz}, 2 \mathrm{H}), 1.40(\mathrm{p}, J=6.7 \mathrm{~Hz}, 2 \mathrm{H}), 1.31-1.17(\mathrm{~m}, 8 \mathrm{H})$, $0.85(\mathrm{t}, J=6.8 \mathrm{~Hz}, 3 \mathrm{H}) .{ }^{13} \mathrm{C}$ NMR $\left(126 \mathrm{MHz}, \mathrm{DMSO}-d_{6}\right) \delta 170.9$, $155.5,130.5,127.6,122.7,118.9,115.4,38.7,37.5,31.2,29.0,28.4$, 26.3, 22.0, 13.9. HRMS (ESI) calcd for $\mathrm{C}_{15} \mathrm{H}_{23} \mathrm{NO}_{2}[\mathrm{M}+\mathrm{Na}]^{+}$ 272.1621; found 272.1624.

N-Heptyl-3-(2-hydroxyphenyl)propanamide (n-Heptyl Aminolysis Product of BMP). To a solution of 3,4-dihydrocoumarin ( $95 \mu \mathrm{L}, 0.746$ $\mathrm{mmol}$ ) in dry $\mathrm{MeCN}$ at $\mathrm{rt}$ under an argon atmosphere was added $n$ heptylamine $(220 \mu \mathrm{L}, 1.49 \mathrm{mmol})$ and the reaction was stirred for 16 h. The mixture was then dissolved in $\mathrm{CHCl}_{3}(50 \mathrm{~mL})$ and washed with $1 \mathrm{M} \mathrm{HCl}(25 \mathrm{~mL})$, water $(25 \mathrm{~mL})$, and brine $(25 \mathrm{~mL})$. The organic phase was dried over $\mathrm{Na}_{2} \mathrm{SO}_{4}$, concentrated, and purified by flash chromatography using EtOAc/hexanes $30 \%$ to afford the product (0.711 mmol, 95\% yield) as a white solid: ${ }^{1} \mathrm{H}$ NMR $(500 \mathrm{MHz}$, DMSO- $\left.d_{6}\right) \delta 9.28(\mathrm{~s}, 1 \mathrm{H}), 7.75(\mathrm{t}, J=5.3 \mathrm{~Hz}, 1 \mathrm{H}), 7.02(\mathrm{~d}, J=7.8 \mathrm{~Hz}$, $9 \mathrm{H}), 6.98(\mathrm{t}, J=8.3 \mathrm{~Hz}, 1 \mathrm{H}), 6.75(\mathrm{~d}, J=7.9 \mathrm{~Hz}, 1 \mathrm{H}), 6.68(\mathrm{t}, J=7.4$ $\mathrm{Hz}, 1 \mathrm{H}), 3.01(\mathrm{q}, J=6.7 \mathrm{~Hz}, 2 \mathrm{H}), 2.71(\mathrm{t}, J=7.7 \mathrm{~Hz}, 2 \mathrm{H}), 2.31(\mathrm{~d}, J=$ $7.9 \mathrm{~Hz}, 3 \mathrm{H}), 1.35(\mathrm{p}, J=7.0 \mathrm{~Hz}, 2 \mathrm{H}), 1.31-1.15(\mathrm{~m}, 8 \mathrm{H}), 0.86(\mathrm{t}, J=$ $6.9 \mathrm{~Hz}, 3 \mathrm{H}) .{ }^{13} \mathrm{C}$ NMR $\left(126 \mathrm{MHz}, \mathrm{DMSO}-d_{6}\right) \delta 171.6,155.0,129.6$ 127.5, 126.9, 118.8, 114.9, 38.4, 35.4, 31.2, 29.1, 28.4, 26.3, 25.7, 22.0, 13.9. HRMS (ESI) calcd for $\mathrm{C}_{16} \mathrm{H}_{25} \mathrm{NO}_{2}[\mathrm{M}+\mathrm{Na}]^{+} 286.1778$; found 286.1792 .

5-Hydroxy-1,3-phenylene Diacetate (Byproduct of n-Heptyl Aminolysis of 4). Benzene-1,3,5-triyl triacetate 4 (0.977 g, 3.87 $\mathrm{mmol}$ ) and DMF (50 mL) were cooled to $-40{ }^{\circ} \mathrm{C}$ before dropwise addition of $n$-heptylamine (b) $(576 \mu \mathrm{L}, 3.87 \mathrm{mmol})$. The reaction mixture was allowed to slowly warm to $\mathrm{rt}$ over $6 \mathrm{~h}$. The reaction mixture was then poured into EtOAc and washed extensively with DI $\mathrm{H}_{2} \mathrm{O}$ followed by brine. The organics were dried over $\mathrm{Na}_{2} \mathrm{SO}_{4}$ and the volatiles were removed in vacuo yielding a crude oil. The crude mixture was purified via column chromatography (40\% EtOAc in hexanes; $\left.R_{\mathrm{f}} \sim 0.4\right)$ to yield the aminolysis product $(480 \mathrm{mg}, 60 \%)$ as a white solid. The NMR data is consistent with the literature. ${ }^{39}{ }^{1} \mathrm{H}$ NMR $\left(500 \mathrm{MHz}\right.$, DMSO- $\left.d_{6}\right): \delta 10.02(\mathrm{~s}, 1 \mathrm{H}), 6.43(\mathrm{~d}, 2 \mathrm{H}, J=2.0$ $\mathrm{Hz}), 6.38(\mathrm{t}, 1 \mathrm{H}, J=2.0 \mathrm{~Hz}), 2.23(\mathrm{~s}, 6 \mathrm{H}) .{ }^{13} \mathrm{C} \mathrm{NMR}(126 \mathrm{MHz}$, DMSO- $\left.d_{6}\right) \delta 168.8,158.5,151.4,106.6,106.4,20.8$. IR $\left(\mathrm{CH}_{3} \mathrm{CN}\right)$ : $\nu_{\mathrm{C}=\mathrm{O}} 1768 \mathrm{~cm}^{-1}$.

3,5-Dihydroxyphenyl Acetate (Byproduct of n-Heptyl Aminolysis of 4). Prepared for verification using a general phloroglucinol acetylation procedure provided in the literature. ${ }^{39}$ To phloroglucinol $(500 \mathrm{mg}, 3.96 \mathrm{mmol})$ in pyridine $(10 \mathrm{~mL})$ was added acetic anhydride (445 mg, $4.36 \mathrm{mmol}$ ) and the reaction mixture was allowed to reflux for $3 \mathrm{~h}$ before cooling to $\mathrm{rt}$. The solvent was removed in vacuo and the residue was purified via column chromatography (1:1 EtOAc:hexanes). After removal of volatiles, a clear oil was obtained $(500 \mathrm{mg}$, 
$75 \%)$. NMR data, recorded in DMSO- $d_{6}$, is consistent with the structure of the compound. ${ }^{40} \mathrm{H}$ NMR ( $\left.500 \mathrm{MHz}, \mathrm{DMSO}-d_{6}\right): \delta 9.47$ $(\mathrm{s}, 2 \mathrm{H}), 6.09(\mathrm{t}, 1 \mathrm{H}, J=2.0 \mathrm{~Hz}), 5.94(\mathrm{~d}, 2 \mathrm{H}, J=2.0 \mathrm{~Hz}), 2.19(\mathrm{~s}, 3 \mathrm{H})$ (peak at $2.08 \mathrm{ppm}$ is $\left.\mathrm{CH}_{3} \mathrm{CN}\right) \cdot{ }^{13} \mathrm{C}$ NMR $\left(126 \mathrm{MHz}, \mathrm{DMSO}-d_{6}\right) \delta$ $168.9,158.7,151.9,100.1,99.9,20.9$. IR $\left(\mathrm{CH}_{3} \mathrm{CN}\right): \nu_{\mathrm{C}=\mathrm{O}} 1764 \mathrm{~cm}^{-1}$.

Aminolysis Kinetics. Kinetics of the aminolysis of BTF, BTP, BMF, BMP, $\mathbf{1 b}, \mathbf{2 b b}, \mathbf{4}, \mathbf{5 b}, \mathbf{6 b b}$, at $24.0 \pm 0.2{ }^{\circ} \mathrm{C}$ in acetonitrile was followed as described above on an infrared spectrophotometer coupled with a stopped-flow injection system and equipped with a $100 \mu \mathrm{m}$ path length stopped flow cell. In general, at least a 15 -fold excess of $n$ heptylamine was used for each run. Each average $k_{\text {obs }}$ was determined as the average of 3-6 independent runs. Concentrations of compounds were determined utilizing a microbalance and volumetric flasks. See the Supporting Information for additional details.

\section{ASSOCIATED CONTENT}

\section{(S) Supporting Information}

The Supporting Information is available free of charge on the ACS Publications website at DOI: 10.1021/acs.joc.6b01867.

NMR data, aminolysis kinetics data and mathematical predictions, computational details (including energies and coordinates of geometry-minimized structures), and details of X-ray data collection and structure refinement (PDF)

Crystallographic data of compounds BTP, 5a, and 1c (CIF)

\section{AUTHOR INFORMATION}

\section{Corresponding Author}

*E-mail: castellano@chem.ufl.edu.

\section{Present Address}

${ }^{\dagger}$ MERLN Institute for Technology-Inspired Regenerative Medicine, Maastricht University, PO Box 616, 6200 MD Maastricht, The Netherlands.

\section{Notes}

The authors declare no competing financial interest.

\section{ACKNOWLEDGMENTS}

Acknowledgement is made to the donors of the American Chemical Society Petroleum Research Fund (PRF \# 51880ND4) and the University of Florida (graduate fellowships to M.B.B., R.B.F., and A.J.L.) for support of this research. Additional support for A.A. is acknowledged from the National Science Foundation REU program (CHE-0353828). The authors are grateful to the University of Florida HighPerformance Computing Center for providing computational resources and both the University of Florida and the National Science Foundation (CHE-0821346) for funding the X-ray equipment. We would finally like to thank Prof. Leslie Murray for stopped-flow IR training and insightful advice and Daan van der Zwaag for assistance in the mathematical analysis of the reaction kinetics.

\section{REFERENCES}

(1) (a) Lee, J.-S.; Lee, J. W.; Kang, N.; Ha, H.-H.; Chang, Y.-T. Chem. Rec. 2015, 15, 495-510. (b) Vaxelaire, C.; Winter, P.; Christmann, M. Angew. Chem., Int. Ed. 2011, 50, 3605-3607.

(2) Brauch, S.; van Berkel, S. S.; Westermann, B. Chem. Soc. Rev. 2013, 42, 4948-4962.

(3) Fries, H. H. J. Chem. Soc., Trans. 1886, 49, 314-316.

(4) Cuthbertson, W. W.; Moffatt, J. S. J. Chem. Soc. 1948, 561-564.

(5) (a) Jagadeesh Kumar, G.; Sriramkumar Bomma, H. V. S.; Srihari, E.; Shrivastava, S.; Naidu, V. G. M.; Srinivas, K.; Jayathirtha Rao, V. Med. Chem. Res. 2013, 22, 5973-5981. (b) Banerjee, R.; Brown, D. R.;
Weerapana, E. Synlett 2013, 24, 1599-1605. (c) Lim, J.; Simanek, E. E. Adv. Drug Delivery Rev. 2012, 64, 826-835.

(6) Gamez, P.; Reedijk, J. Eur. J. Inorg. Chem. 2006, 2006, 29-42.

(7) Blotny, G. Tetrahedron 2006, 62, 9507-9522.

(8) (a) Kubo, T.; Figg, C. A.; Swartz, J. L.; Brooks, W. L. A.; Sumerlin, B. S. Macromolecules 2016, 49, 2077-2084. (b) Figg, C. A.; Kubo, T.; Sumerlin, B. S. ACS Macro Lett. 2015, 4, 1114-1118.

(9) Ramesh, A.; Syama Sundar, B.; Radhakrishna Murti, P. S. J. Indian Chem. Soc. 1995, 72, 697-700.

(10) Baker, M. B.; Ghiviriga, I.; Castellano, R. K. Chem. Sci. 2012, 3, 1095-1099.

(11) Li, Y.; Lampkins, A. J.; Baker, M. B.; Sumpter, B. G.; Huang, J.; Abboud, K. A.; Castellano, R. K. Org. Lett. 2009, 11, 4314-4317.

(12) (a) Wilson, M. R.; Taylor, R. E. Angew. Chem., Int. Ed. 2013, 52, 4078-4087. (b) Gold, B.; Dudley, G. B.; Alabugin, I. V. J. Am. Chem. Soc. 2013, 135, 1558-1569. (c) Agard, N. J.; Prescher, J. A.; Bertozzi, C. R. J. Am. Chem. Soc. 2004, 126, 15046-15047. (d) Stirling, C. J. M. Tetrahedron 1985, 41, 1613-1666.

(13) Lampkins, A. J.; Li, Y.; Al Abbas, A.; Abboud, K. A.; Ghiviriga, I.; Castellano, R. K. Chem. - Eur. J. 2008, 14, 1452-1463.

(14) (a) Um, I.-H.; Bae, A. R. J. Org. Chem. 2011, 76, 7510-7515. (b) Galabov, B.; Ilieva, S.; Hadjieva, B.; Atanasov, Y.; Schaefer, H. F. J. Phys. Chem. A 2008, 112, 6700-6707. (c) Um, I.-H.; Jeon, S.-E.; Seok, J.-A. Chem. - Eur. J. 2006, 12, 1237-1243. (d) Neuvonen, H.; Neuvonen, K.; Koch, A.; Kleinpeter, E.; Pasanen, P. J. Org. Chem. 2002, 67, 6995-7003. (e) Koh, H. J.; Kim, S. I.; Lee, B. C.; Lee, I. J. Chem. Soc., Perkin Trans. 2 1996, 1353-1357. (f) Menger, F. M.; Smith, J. H. J. Am. Chem. Soc. 1972, 94, 3824-3829.

(15) (a) Yi, G.-Q.; Zeng, Y.; Xia, X.-F.; Xue, Y.; Kim, C.-K.; Yan, G.S. Chem. Phys. 2008, 345, 73-81. (b) Sung, D. D.; Koo, I. S.; Yang, K.; Lee, I. Chem. Phys. Lett. 2006, 426, 280-284.

(16) Maude, A. B.; Williams, A. J. Chem. Soc., Perkin Trans. 2 1997, 179-184.

(17) Izbicka, E.; Bolen, D. W. J. Am. Chem. Soc. 1978, 100, 76257628.

(18) (a) Svirbely, W. J.; Blauer, J. A. J. Am. Chem. Soc. 1961, 83, 4115-4118. (b) Svirbely, W. J. J. Am. Chem. Soc. 1959, 81, 255-257. (c) Svirbely, W. J. J. Phys. Chem. 1958, 62, 380-380.

(19) Friedman, M. H.; White, R. R. AIChE J. 1962, 8, 581-586.

(20) Haines, A. H.; Hughes, D. L. Acta Crystallogr., Sect. E: Struct. Rep. Online 2009, 65, o3279.

(21) While the protonation state of the products and reactants (i.e., - $\mathrm{OH}$ vs. - $\mathrm{O}-$ ) have not been measured under the reaction conditions, significant deprotonation is not expected given the difference in $\mathrm{p} K_{\mathrm{a}}$ between phloroglucinol (estimated; 20-25) and $n$ butylammonium (18.3) in acetonitrile. See Kütt, A.; Leito, I.; Kaljurand, I.; Sooväli, L.; Vlasov, V. M.; Yagupolskii, L. M.; Koppel, I. A. J. Org. Chem. 2006, 71, 2829-2838 for molecules serving as the basis of the $\mathrm{p} K_{\mathrm{a}}$ estimation.

(22) Hansch, C.; Leo, A.; Taft, R. W. Chem. Rev. 1991, 91, 165-195.

(23) (a) Neuvonen, H.; Neuvonen, K. J. Chem. Soc., Perkin Trans. 2 1999, 1497-1502. (b) Bromilow, J.; Brownlee, R. T. C.; Craik, D. J.; Fiske, P. R.; Rowe, J. E.; Sadek, M. J. Chem. Soc., Perkin Trans. 2 1981, $753-759$.

(24) Um, I.-H.; Lee, J.-Y.; Fujio, M.; Tsuno, Y. Org. Biomol. Chem. 2006, 4, 2979-2985.

(25) Neuvonen, H.; Neuvonen, K.; Koch, A.; Kleinpeter, E. J. Phys. Chem. A 2005, 109, 6279-6289.

(26) Reed, A. E.; Curtiss, L. A.; Weinhold, F. Chem. Rev. 1988, 88, 899-926.

(27) (a) Chattaraj, P. K.; Sarkar, U.; Roy, D. R. Chem. Rev. 2006, 106, 2065-2091. (b) Parr, R. G.; Szentpály, L. v.; Liu, S. J. Am. Chem. Soc. 1999, 121, 1922-1924.

(28) (a) Galabov, B.; Ilieva, S.; Schaefer, H. F. J. Org. Chem. 2006, 71, 6382-6387. (b) Kollman, P.; McKelvey, J.; Johansson, A.; Rothenberg, S. J. Am. Chem. Soc. 1975, 97, 955-965.

(29) Shaik, S.; Shurki, A.; Danovich, D.; Hiberty, P. C. Chem. Rev. 2001, 101, 1501-1540. 
(30) Boese, R.; Bläser, D.; Billups, W. E.; Haley, M. M.; Maulitz, A. H.; Mohler, D. L.; Vollhardt, K. P. C. Angew. Chem., Int. Ed. Engl. 1994, 33, 313-317.

(31) (a) Stanger, A. Chem. Commun. 2009, 1939-1947. (b) Bürgi, H.-B.; Baldridge, K. K.; Hardcastle, K.; Frank, N. L.; Gantzel, P.; Siegel, J. S.; Ziller, J. Angew. Chem., Int. Ed. Engl. 1995, 34, 1454-1456. (c) Siegel, J. S. Angew. Chem., Int. Ed. Engl. 1994, 33, 1721-1723.

(32) Hall, H. K.; Zbinden, R. J. Am. Chem. Soc. 1958, 80, 6428-6432.

(33) Leitão, M. L. P.; Pilcher, G.; Meng-Yan, Y.; Brown, J. M.; Conn, A. D. J. Chem. Thermodyn. 1990, 22, 885-891.

(34) (a) Houk, K. N.; Jabbari, A.; Hall, H. K.; Alemán, C. J. Org. Chem. 2008, 73, 2674-2678. (b) Brown, H. C.; Brewster, J. H.; Shechter, H. J. Am. Chem. Soc. 1954, 76, 467-474. (c) Carothers, W. H.; Dorough, G. L.; Natta, F. J. v. J. Am. Chem. Soc. 1932, 54, 761772.

(35) Sousa, C. C. S.; Matos, M. A. R.; Santos, L. M. N. B. F.; Morais, V. M. F. J. Chem. Thermodyn. 2013, 67, 210-216.

(36) Matos, M. A. R.; Sousa, C. C. S.; Morais, V. M. F. J. Chem. Thermodyn. 2009, 41, 308-314.

(37) Wheeler, S. E.; Houk, K. N.; Schleyer, P. v. R; Allen, W. D. J. Am. Chem. Soc. 2009, 131, 2547-2560.

(38) Bazin, M.-A.; Bodero, L.; Tomasoni, C.; Rousseau, B.; Roussakis, C.; Marchand, P. Eur. J. Med. Chem. 2013, 69, 823-832.

(39) Sapkota, K.; Roh, E.; Lee, E.; Ha, E.-M.; Yang, J.-H.; Lee, E.-S.; Kwon, Y.; Kim, Y.; Na, Y. Bioorg. Med. Chem. 2011, 19, 2168-2175.

(40) Carnduff, J.; Miller, J. A.; Stockdale, B. R.; Larkin, J.; Nonhebel,

D. C.; Wood, H. C. S. J. Chem. Soc., Perkin Trans. 1 1972, 692-699. 